\title{
Nanotechnology-based approaches in anticancer research
}

This article was published in the following Dove Press journal:

International Journal of Nanomedicine

8 August 2012

Number of times this article has been viewed

\author{
Nasimudeen R Jabir ${ }^{\prime}$ \\ Shams Tabrez' \\ Ghulam Md Ashraf ${ }^{2}$ \\ Shazi Shakil ${ }^{3}$ \\ Ghazi A Damanhouri ${ }^{4}$ \\ Mohammad A Kamal' \\ Metabolomics and Enzymology \\ Unit, ${ }^{2}$ Proteomics and Structural \\ Biology Unit, ${ }^{3}$ Enzoinformatics Unit, \\ ${ }^{4} \mathrm{Hematology}$ Research Unit, King \\ Fahd Medical Research Center, \\ King Abdulaziz University, Jeddah, \\ Saudi Arabia
}

Correspondence: Mohammad Amjad Kamal King Fahd Medical Research Center, King Abdulaziz University, PO Box 80216, Jeddah 21589,

Saudi Arabia

Tel +96626401000

Fax +96626952076

Emailma.kamal@live.com

\begin{abstract}
Cancer is a highly complex disease to understand, because it entails multiple cellular physiological systems. The most common cancer treatments are restricted to chemotherapy, radiation and surgery. Moreover, the early recognition and treatment of cancer remains a technological bottleneck. There is an urgent need to develop new and innovative technologies that could help to delineate tumor margins, identify residual tumor cells and micrometastases, and determine whether a tumor has been completely removed or not. Nanotechnology has witnessed significant progress in the past few decades, and its effect is widespread nowadays in every field. Nanoparticles can be modified in numerous ways to prolong circulation, enhance drug localization, increase drug efficacy, and potentially decrease chances of multidrug resistance by the use of nanotechnology. Recently, research in the field of cancer nanotechnology has made remarkable advances. The present review summarizes the application of various nanotechnology-based approaches towards the diagnostics and therapeutics of cancer.
\end{abstract}

Keywords: cancer, diagnosis, drug delivery, nanoparticle, nanotechnology, treatment

\section{Introduction}

Cancer is a highly heterogeneous complex disease that encompasses a group of disorders characterized by continuous indefinite growth. ${ }^{1}$ Through the annals of history, the malaise of cancer has ailed humans. Despite impressive advances in cancer biology, it is the leading cause of death worldwide and remains a challenge. There are over 200 different types of cancer reported all over the globe. ${ }^{2}$ In 2008, approximately 12.7 million cancer cases were reported, causing approximately 7.6 million cancer deaths, out of which $64 \%$ of the deaths were reported from economically developing countries. ${ }^{3}$ The complexity of this disease at genetic and phenotypic levels clarifies its clinical diversity and therapeutic resistance. There is a 5-year relative survival rate of cancer patients, ${ }^{4}$ which provides potential opportunities for early diagnosis and improved treatment, which in turn is highly desirable because of widespread occurrence, high death rate, and recurrence after treatment. ${ }^{5}$

Nanotechnology is an interdisciplinary research field developed with an amalgamation of chemistry, engineering, biology, and medicine, and has various useful applications in cancer biology, such as early detection of tumors, discovery of cancer biomarkers, and development of novel treatments. ${ }^{6}$ It is a rapidly evolving and expanding discipline that has gained public and media interest worldwide. Use of nanotechnology in cancer biology has provided hope within scientific communities of developing novel cancer therapeutic strategies. Nanotechnology involves the creation and/or manipulation of materials at nanometer scale, either by scaling up from single 
groups of atoms or by refining or reducing bulk materials into nanoparticles (NPs). ${ }^{7}$ NPs are typically several hundred nanometers in size and can offer unprecedented interactions with biomolecules present both on the cell surface as well as inside the cell. ${ }^{8}$ NPs can be engineered as nanoplatforms for effective and targeted delivery of drugs, and imaging labels by overcoming many biological, biophysical, and biomedical barriers. For in vitro and ex vivo applications, the advantages of state-of-the-art nanodevices such as nanochips and nanosensors over traditional methods are quite obvious. ${ }^{9,10}$ A variety of NPs are used for diagnosis-cum-therapy of different cancer types, by visualizing tumors and carrying out targeted delivery of drugs with reduced toxic side effects. Cancer related examples of nanodevices include quantum dots (QDs), carbon nanotubes (CNTs), paramagnetic NPs, liposomes, gold NPs (GNPs), magnetic resonance imaging (MRI) contrast agents for intraoperative imaging, and a novel NP-based method for high-specificity detection of DNA and protein. ${ }^{6,11-15}$

Recent advances have led to development of bioaffinity NP probes for molecular and cellular imaging, targeted NP drugs for cancer therapy, and integrated nanodevices for early screening and detection of cancer. These developments raise exciting opportunities for personalized oncology in which genetic and protein biomarkers are used to diagnose and treat cancer, based on the molecular profiles of individual patients. However, several barriers do exist for in vivo applications of nanodevices in preclinical and clinical use of nanotechnology. Amongst them are biocompatibility, in vivo kinetics, tumor-targeting efficacy, acute and chronic toxicity, ability to escape the reticuloendothelial system, and cost-effectiveness. ${ }^{6,16}$ The development of novel nanotechnology-based approaches towards cancer treatment provides a new ray of hope in the cancer research field. The present review article summarizes the application of various nanotechnology-based approaches towards the diagnostics and therapeutics of cancer.

\section{Use of nanotechnology in cancer treatment \\ Current therapies and their drawbacks}

In the past decade, remarkable progress has been made towards understanding the proposed hallmarks of cancer progression and treatment. With time, the cancer burden is changing for combined types as well as individual types of cancer. However, with ever-increasing incidence, the clinical management of cancer continues to be a grim challenge for the twenty-first century. Over the past couple of decades, a huge amount of detailed data have been amassed regarding the basic biological processes that become perturbed in cancer, such as disturbances in growth-factor binding, signal transduction, gene transcription control, cell-cycle checkpoints, apoptosis, and angiogenesis. ${ }^{17}$ These in turn have prompted the search for rational anticancer drugs and produced a record number of novel compounds, currently being used in cancer treatment trials.

A number of targeted drugs are licensed for routine clinical use, including rituximab, trastuzumab, imatinib, gefitinib, bevacizumab, lapatinib, and cetuximab. ${ }^{17}$ Present therapeutic approaches are based on rectifying the damaging mechanism of the genes or by stopping the blood supply to the cancer cells or by destroying the cancer cells itself. ${ }^{18}$ Conventional treatment options like surgical excision to remove cancerous parts, radiation therapy, and chemotherapy have their own limitations. Surgery cannot be applied for all types of cancers and might result in loss of an organ, coupled with the risk of cancer recurrence. The radiation approach kills cancerous cells, but it also damages the surrounding healthy cells. ${ }^{18}$ The most common therapeutic approach, chemotherapy, is used either alone or in combination with other therapeutic approaches that kill cancer cells by drug toxicity or by preventing cell division, either by stopping the nutrient uptake or by inhibiting the mechanism responsible for cell division. ${ }^{19}$ However, this approach is gross and rarely successful for advanced stages of cancer, as pharmacologically active cancer drugs reach the tumor site with poor specificity and doselimiting toxicity. ${ }^{20}$ Currently available chemotherapeutic agents are time-tested and confer good disease-free survival only for a limited period of time. Nevertheless, nontarget tissue toxicity and drug resistance curtails the utility of these agents. There is scope to develop newer agents or site-specific delivery systems to transfer these chemotherapeutic agents, which can nullify the major obstacles of toxicity and drug resistance. ${ }^{21}$ The destruction of cancer cells with minimum harm to healthy tissues and delivery of high doses of drug molecules to tumor sites for maximum treatment efficacy are the needs of the hour.

\section{Will nanotechnology-based approaches help in cancer treatment?}

Cancer nanotechnology is a rapidly growing field and has made a remarkable contribution to treatment strategies by enabling site-specific release of chemotherapeutic agents, based on their physicochemical characteristics and biological attributes. ${ }^{21,22}$ Several stability and drug-payload studies on NP formulations have shown that they are quite stable with 
high carrier capacity, and are suitable for administration of both hydrophilic and hydrophobic substances by various routes. ${ }^{23}$ They also have the ability to carry loaded active drugs to cancer cells by selectively utilizing the unique pathophysiology of tumors. ${ }^{22}$ Due to the advances in synthetic chemistry over the last few decades, different biological nanomaterials have been developed, which can be used for a variety of biological therapies, such as drug delivery, cancer diagnosis, treatment, and imaging. ${ }^{24}$

The nanotechnology-based drug-delivery system (NDDS) targeted specifically towards cancer cells has several advantages over conventional therapies, such as longer shelf life, improvement in biodistribution of cancer drugs, and administration of both hydrophilic and hydrophobic substances, through oral, nasal, parenteral, and intraocular routes. ${ }^{19}$

\section{Current NP systems for cancer therapeutics}

There are a variety of NP systems currently being explored for cancer therapeutics. ${ }^{25}$ The material properties of some NP systems have been developed to enhance their delivery to the tumor site directly. ${ }^{26}$ Functionalization of NPs by the incorporation of a hydrophilic polymer creates a stealth surface from opsonization. ${ }^{26}$ Currently used NPs in cancer therapeutics include dendrimers, liposomes, lipid NPs (LNPs), polymeric NPs (PNPs), micelles, protein NPs, ceramic NPs, viral NPs, metallic NPs, and CNTs. ${ }^{26-28}$ Despite extensive research on NP systems for cancer therapeutics, there are only a few NDDSs approved by the US Federal Drug Administration and European Medicines Agency. Specifically, the NDDSs that have been approved include liposomal doxorubicin (Myocet; Elan Pharmaceuticals, Cedar Knolls, NJ), PEGylated liposomal doxorubicin (Doxil; Ortho Biotech, and Caelyx; ScheringPlough), PEGylated liposomal daunorubicin (DaunoXome; Diatos), and the recently approved albumin-bound paclitaxelloaded NPs (Abraxane; Abraxis Bioscience). ${ }^{26}$

\section{Various approaches towards cancer treatment with different nanomaterials}

Targeted drug delivery via nanocarriers

The development of targeted therapy represents an exciting approach towards cancer treatment. ${ }^{21}$ Different targeting strategies suggest the potential effect of NP systems and will possibly revolutionize current methods in cancer treatment. Different significant events in cancer mechanisms like angiogenesis, uncontrolled cell proliferation, and tumor mass are the targets for NP systems. ${ }^{26}$ The effectiveness of NP carrier systems reflects their ability to reduce the tumor or related events without damaging healthy tissues. Moreover, the major improvements offered by NP systems include higher efficacy, lesser side effects, site specificity, efficient delivery, and overcoming multidrug resistance (MDR). ${ }^{29}$

\section{Targeting tumor cells}

The most common targeting strategy is ligand-mediated specific interactions between NPs and cancer cell surface. Longer circulation times and easier endocytosis are the significant factors that need to be considered while choosing target moieties for effective delivery of NPs. ${ }^{30}$ These ligand-targeted NPs are expected to deliver cytotoxic agents selectively and specifically to tumor cells via receptormediated endocytosis, thereby enhancing intracellular drug accumulation. A variety of tumor-targeting ligands, such as antibodies, folate or growth factors, and cytokines have been used to facilitate the uptake of carriers into target cells. ${ }^{31}$ Moreover, monoclonal antibodies and antibody fragments can reduce immunogenicity and improve pharmacokinetics. ${ }^{32}$ Artificially engineered antibodies have also been reported as a conjugate to thermosensitive liposomes (affisomes) and to poly-(D,L-lactic acid)-polyethylene glycol (PLA-PEG) maleimide copolymer for the delivery of paclitaxel. ${ }^{33,34}$

Internalization in cancer cells is an important step, because it reduces the dispersal of the drug outside the cancerous cell and can enhance the therapeutic potential of the said drug. ${ }^{35-37}$ Passive targeting approaches have also been reported for the delivery of NPs in angiogenesis as a compensatory mechanism of diffusion. It depends upon the properties of NPs, such as, size, surface nature, and circulation half-life. ${ }^{19,38}$ Passive targeting also involves the use of other innate characteristics of NPs (viz charge) capable of inducing tumor targeting. Cationic liposomes are reported to bind by electrostatic interactions to negatively charged phospholipid head groups, preferentially expressed on tumor endothelial cells. ${ }^{19,39}$ Human cervical carcinoma cells devoid of folate receptor are incapable of cellular uptake of folateconjugated NPs. ${ }^{40}$ Similarly, enhanced antiproliferative potential of epirubicin going from folate receptor $(-)$ to folate receptor $(++)$ cells was also observed..$^{41}$ The uptake of folic acid-conjugated doxorubicin by HeLa cells has also been reported. ${ }^{40}$ The anticancer activity of transferring-conjugated solid-lipid NPs of curcumin on the MCF-7 cell line is also evident. ${ }^{42}$ Several such studies suggested the potential of targeted therapeutic nanoparticles (TNPs) as effective anticancer drug-delivery systems..$^{2,22,25,40,43}$ In an in vivo animal study, targeted TNP-delivered paclitaxel was mainly located 
in tumor cells, while nontargeted TNP-delivered paclitaxel was detected at intercellular level. ${ }^{44}$

\section{Targeting the tumor microenvironment}

It has been debated that the tumor microenvironment enhanced permeability and retention (EPR) effect might be a key rationale for the development of nanoscale carriers to solid tumors. As an outcome of EPR, nanotherapeutics are expected to improve drug and detection probe delivery, have less adverse effects, and thus result in improved detection and treatment of tumors. ${ }^{45}$ Exploiting the abnormal tumor microenvironment for selective and homogeneous delivery of nanomedicines to tumor sites is another way of cancer treatment. $^{46}$

The caveolae (endothelium transcytosis vesicles)-induced accumulation of an albumin-bound nanomedicine (Abraxane) is initiated by the binding of albumin to a cell surface glycoprotein receptor, suggesting that caveolae targeting might provide a universal portal to pump drugs out of the blood into nearby tissue. ${ }^{47}$ Moreover, arginine-glycine-aspartic acid (RGD) motif has been found to exhibit a strong affinity and selectivity for cell surface in many proteins, thus proclaiming it to be a suitable ligand for tumor targeting by therapeutic NPs. ${ }^{48}$

\section{Targeting recurrent and drug-resistant cancers}

Due to the lack of specific ligands, the specific killing of recurrent cancer cells by using targeted TNPs is still unexplored. Although many studies have illustrated the potential use of TNPs to minimize drug resistance, the lack of specific ligands for drug-resistant cancer cells limits the application of targeted TNPs to these aggressive populations. However, targeting of well-progressed cancer environments like recurrence and metastasis is still a challenge. Advanced knowledge of the molecular mechanisms of late-stage cancer has given new leads to target metastatic cancer with NP systems. Moreover, PEGylated liposome modified with a fibronectinmimetic peptide has been reported to target metastatic colon cancer cells (which overexpress integrins $\alpha 5 \beta 1) .{ }^{49}$

\section{Nanotechnology-based drug-delivery systems}

Nanotechnology-based systems can be used to deliver therapeutic entities such as small-molecule drugs, peptides, proteins, and nucleic acids, either alone or in combinations. ${ }^{48,50}$ Their properties could be attributed to their small sizes, lower drug toxicity, maximized bioavailability, cell death, and modification of drug pharmacokinetics. ${ }^{51-53}$ Figure 1 depicts several nanotechnology based drug delivery systems used in recent years. Several anticancer drugs, such as paclitaxel, doxorubicin, 5-fluorouracil, and dexamethasone, have been successfully formulated using nanomaterials. ${ }^{51}$ Polylactic/ glycolic acid (PLGA)-based NPs have been formulated to encapsulate dexamethasone. ${ }^{51}$ It has also been reported that NPs can escape from the vasculature through the leaky endothelial tissue that surrounds the tumor ${ }^{54}$ and can accumulate in certain solid tumors via the EPR effect. ${ }^{55}$ In contrast, tumor-targeted NPs can enter tumor cells from the extracellular space via receptor-mediated endocytosis. ${ }^{56}$ Significant progress has been made in tumor-targeted nanotherapeutics, and some are already in clinical trials or have been approved by the FDA. ${ }^{37}$ Kang et al studied doxorubicin-loaded solidlipid NPs on a doxorubicin-resistant breast cancer cell line (MCF-7/ADR). ${ }^{57}$ Their results showed that doxorubicinloaded solid-lipid NPs efficiently enhanced apoptotic cell death through higher accumulation of doxorubicin in MCF-7/ ADR cells compared with free doxorubicin.

\section{Advantages of NP drug-delivery system}

1. To overcome lack of selectivity of anticancer drugs: The major goal of targeted therapies is to target the chemotherapeutics to cancer cells, which ultimately reduces the side effects. To decrease the toxicity and to enhance the selectivity of existing drugs, many NDDSs have been developed in recent years that target specific sites either actively or passively. ${ }^{19}$

2. To overcome MDR: Cancers such as non-small-cell lung cancer, and rectal cancer may not respond to standard chemotherapy from the beginning, which is known as primary resistance, while some sensitive tumors respond well to chemotherapy drugs initially but develop acquired resistance later. MDR is mostly due to increased efflux pumps in the cell membrane, such as P-glycoprotein (Pgp). The adenosine triphosphate-binding cassette superfamily includes MDR-associated proteins and breast cancerresistant proteins. Several studies reported NP-based drugdelivery systems to overcome MDR. ${ }^{19,58,59}$ It was reported that paclitaxel-loaded NP-based drugs could be introduced inside the cells without triggering the Pgp pump in human colorectal tumor. ${ }^{60}$ Also, paclitaxel entrapped in emulsifying wax NPs was shown to overcome drug resistance in a human colon adenocarcinoma cell line (HCT-15). ${ }^{51}$ The PLGA NPs were reported to moderately reverse MDR activity in MCF-7/ADR cells. ${ }^{59}$ The activity of doxorubicin and Bcl-2-targeted siRNA on multidrug-resistant A2780/AD human ovarian cancer cells was studied by 


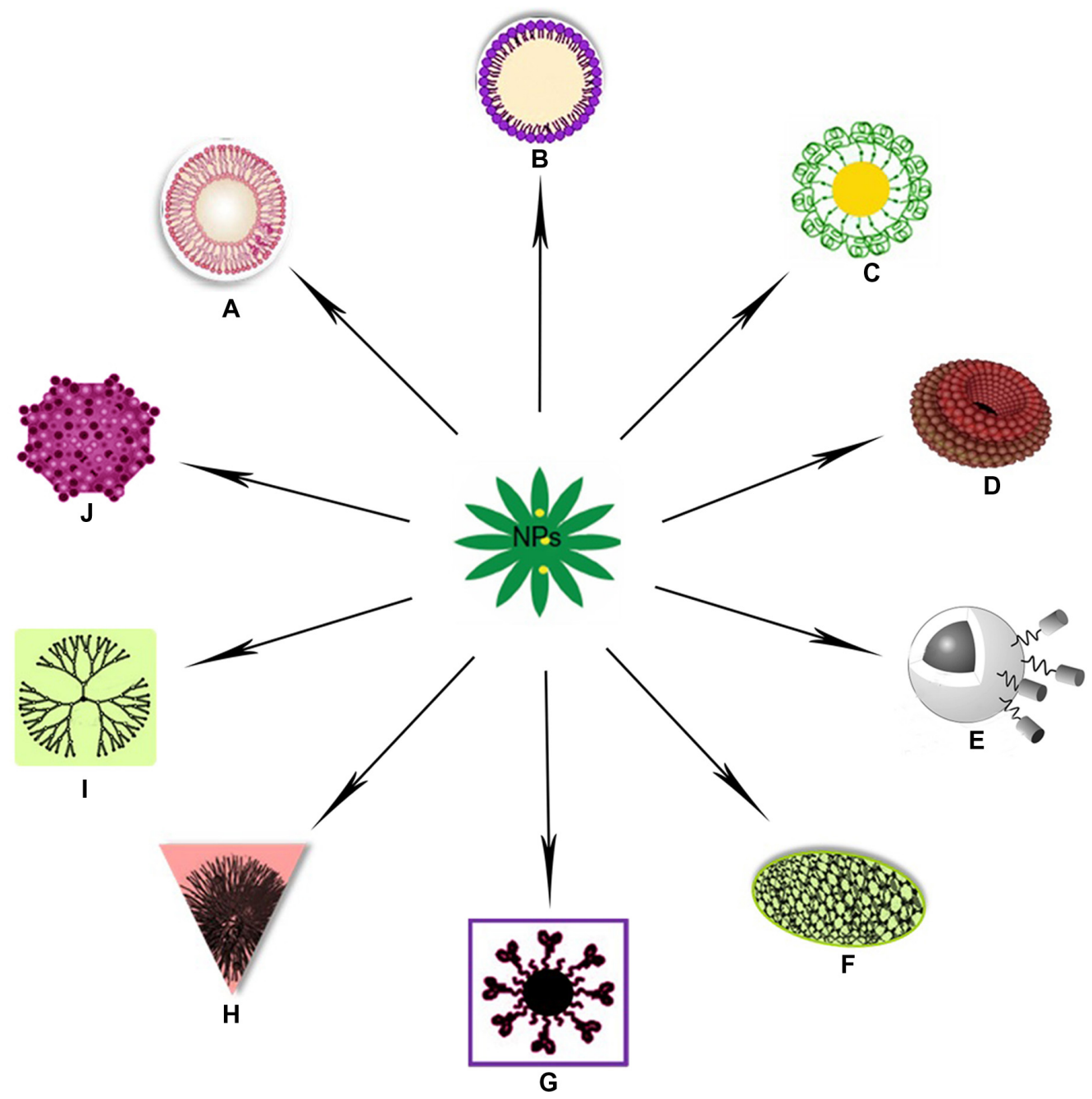

Figure I (A-J) Illustration to clarify the described drug-delivery systems of various nanoparticles (NPs). (A) Liposomal nanoparticle; (B) solid lipid nanoparticle; (C) gold nanoparticle; (D) nanodiamond; (E) magnetic nanovector;220 (F) carbon nanotube; (G) quantum dot nanocarrier; (H) polymeric nanoparticle; (I) dendrimer nanoparticle; (J) virus-mediated nanocarrier. ${ }^{219}$

Chen et al, using mesoporous silica NPs..$^{58}$ They showed that by delivering doxorubicin and Bcl-2 siRNA simultaneously into cancer cells, the Bcl-2 siRNA can effectively silence the Bcl-2 mRNA, significantly suppress non-pump resistance, and substantially enhance the anticancer potential of doxorubicin. Moreover, poloxamer 188 NPs have been reported to overcome MDR in human breast cancer cells. ${ }^{61}$

3. To overcome low aqueous solubility of anticancer drugs: Most of the anticancer drugs exhibit poor solubility, which results in reduced bioavailability, increased chances of food effect, frequent incomplete release in dosage form, and higher interpatient variability. Paclitaxel bound to biocompatible proteins is an injectable nanosuspension, that has been approved by the FDA, and is in phase trials for a variety of cancers. ${ }^{62,63}$

\section{Liposomal nanoparticles as a targeted drug-delivery system}

Liposomes are colloidal carriers, formed spontaneously when certain lipids are hydrated in aqueous media. They consist of an aqueous volume entrapped by one or more bilayers of natural and/or synthetic lipids. They are comparatively stable, biocompatible, biodegradable, self-assembled phospholipid membranes with an inner core where hydrophilic drugs could be encapsulated. Liposomes have been suggested as carriers of antineoplastic and antimicrobial drugs, chelating agents, steroids, vaccines, and genetic materials. ${ }^{64}$ They are efficient vehicles for targeted delivery of hydrophobic drugs without eliciting an immune response. ${ }^{21}$ Drugs with widely varying lipophilicities can be encapsulated in liposomes, either in the phospholipid bilayer, in the entrapped aqueous volume, or at the bilayer interface. Drugs encapsulated within this 
lipid bilayer are, therefore, protected from extra-liposomal reactions that could alter the effectiveness of the drug. ${ }^{65}$ The lipid bilayer could have a marked effect on the pharmacokinetics and biodistribution of LNPs. In one study, Johnston et al reported significant increase in drug-retention properties in LNPs containing sphingomyelin lipid. ${ }^{66}$ Generally, liposomes have advantages over polymer-based NPs for the formulation of cancer therapeutics. ${ }^{67}$ In most of the cases, the lipid membrane structure mimics the most common structure, which provides a remarkable permeability barrier. Moreover, liposome-encapsulated drugs are protected from extraliposomal reactions, which enhance the effectiveness of the said drug.

LNPs encapsulating therapeutic agents or liposomal nanomedicines represent one of the most advanced classes of drug-delivery systems, with several currently in the market and many more in clinical trials. ${ }^{68}$ There are several examples of LNPs for conventional small-molecule drugs. ${ }^{65,69}$ Curcumin's efficacy as a chemotherapeutic agent against several cancers of the stomach, prostate, breast, and lung has been well documented. ${ }^{70,71}$ Cheng et al reported the development of liposomal curcumin encompassing the anticancer curcumin within liposomal formulations. ${ }^{72}$ In another study, liposome preparations of curcumin exhibited superior antiproliferative and apoptotic effects on six pancreatic cancer cells, and also inhibited pancreatic tumor growth in mouse models. ${ }^{73}$ Use of the ionophore method of drug loading allows much higher drug:lipid ratios than the conventional citrate method. ${ }^{74}$ This formulation has given excellent results in studies comparing the efficacy of conventional CHOP (chemotherapy treatment composed of cyclophosphamide, doxorubicin, vincristine, and prednisone) and CHOP in which the vincristine has been replaced by LNP-vincristine. ${ }^{75,76}$ Moreover, increased drug retention of vincristine has been reported to be related to increased drug:lipid ratios. ${ }^{75}$ Lipid-based nanocapsules have given a novel approach to scientific communities for encapsulation of poorly soluble drugs like cisplatin. ${ }^{21}$

\section{Drug delivery via carbon nanotubes}

CNTs have shown great promise as nanoscale vehicles for targeted drug delivery. ${ }^{2}$ In the past, there have been numerous experimental studies performed in vitro and in vivo using antibody-functionalized CNTs loaded with chemotherapeutic agents., ${ }^{2,77-79}$ It has been suggested that CNTs could be used as nanocarriers for delivering drugs into the body via intravenous routes. ${ }^{80}$ Drugs can either attach to the outer surface of CNTs via functional groups or be loaded inside the CNTs. ${ }^{2}$ Nanoscale size and ease of cellular uptake makes single-walled carbon nanotubes (SWCNTs) useful for drug delivery, and their photothermal effects make them potentially useful in a wide range of applications. The poor solubility of SWCNTs could be overcome by functionalization of the surface of the tubes. Multiwalled carbon nanotubes (MWCNTs) have been reported to possess shorter incubation time and relatively higher cytotoxic potential. MWCNT-g-PCA-PTX compared with free drug suggests improved cell penetration of MWCNT-g-PCA-PTX. ${ }^{81}$ The grafting of drugs to SWCNTs can be used as a new tool and useful method for potential drug delivery in cancer patients. ${ }^{82}$

\section{Drug delivery via nanodiamonds}

Nanodiamonds (NDs) are attractive agents for use in medicobiological applications, largely due to their greater biocompatibility than other carbon nanomaterials, stable photoluminescence, commercial availability, minimal cytotoxicity, and ease of purification. ${ }^{83,84} \mathrm{NDs}$ could be functionalized and conjugated to a variety of molecules for the purpose of cell labeling and drug delivery that can improve their solubility, direct them to specific binding sites on target cells and tissues, and reduce their effects on normal tissues. ${ }^{83}$ The diversity of ND functionalization broadens the scope of their potential diagnostic and therapeutic applications. They are suitable for controlled drug-delivery applications because of their capability to release drugs slowly and consistently and have abundant capacity for drug loading due to their large surface area:volume ratio. ${ }^{85,86} \mathrm{~A}$ thin film made of ND clusters loaded with doxorubicin was found to effectively release the drug and kill the target cells. ${ }^{85}$ They could also be used to solubilize and efficiently deliver water-insoluble chemotherapeutic agents to breast and liver tumor cells. ${ }^{58,86}$ NDs can be used for cell labeling and tracing because they do not interrupt cell division or differentiation and have less cytotoxicity as well. They have successfully been used as biomarkers or tracers to label or trace HeLa cells, lung cancer cells, and murine fibroblasts. ${ }^{84,87}$

\section{Virus-mediated nanocarriers for drug delivery}

Different virus-based nanocarriers for drug delivery have also been reported in scientific literature as an emerging nanocarrier platform. ${ }^{43,88-90}$ The versatile hierarchical assembly of viral coat protein subunits provides a natural and easy way of drug packaging. Virus-like particles (VLPs) can easily meet the requirements needed for a drug nanocarrier system, such as biocompatibility, water solubility, and high uptake efficiency. Moreover, VLPs can be modified with polymers such as PEG to improve their half-life in the host 
by moderating their immunogenicity. ${ }^{43}$ Different viruses such as cowpea chlorotic mottle virus (CCMV), a member of the bromovirus group of the Bromoviridae, ${ }^{43}$ cowpea mosaic virus, and red clover necrotic mosaic virus ${ }^{88}$ have been reported as viral nanocarriers. Recently, nanocarriers based on CCMV have also been suggested. ${ }^{89}$ The incorporation of $\mathrm{CdSe} / \mathrm{ZnS}$ semiconductor QDs into brome mosaic virus for the design of intracellular microscopic probes and vectors have also been reported. ${ }^{90}$ GNPs could also be encapsulated in VLPs like MS2 bacteriophage in a similar way. ${ }^{91}$

\section{Magnetic nanovectors for drug delivery}

Use of NP platforms holds the promise of novel and more effective site-specific delivery of therapeutic agents to tumors by magnetic vectoring of magnetically responsive NPs. ${ }^{92}$ Nanovectors based on the three ferromagnetic elements Co, $\mathrm{Ni}$, and $\mathrm{Fe}$ can be used either to mediate a hyperthermic effect (predominantly causing tumor necrosis) or to deliver drugs to achieve intratumoral levels. Nickel-based nanomaterials have also been reported for tumor targeting by serving either as inducers of hyperthermia in response to an externally applied magnetic field (as drug-delivery platforms) ${ }^{93}$ or directly as proapoptotic mediators. ${ }^{94}$ Liu et al synthesized a Co- and $\mathrm{Cu}$-based nonviral carrier for DNA transfer in gene therapy. ${ }^{95}$ Strong binding to DNA involves electrostatic attractions as well as intercalation of the ligands between DNA base pairs, and these complexes efficiently condensed free DNA into globular NPs. Magnetite NPs have reportedly been loaded with daunorubicin to overcome MDR of K562-n/VCR human erythroid leukemia cells. ${ }^{96}$

\section{Enzyme-responsive nanoparticles for drug release} Enzyme-responsive NPs (ENPs), such as polymer-based NPs, liposomes, GNPs, and QDs have been introduced recently and the modulation of their physicochemical properties by the enzymes has been accentuated. Unique physical properties of nanomaterials combined with ENPs are designed with high specificity for triggering the stimulus in drug-delivery schemes. ${ }^{97}$ Hydrolases are the most widely used enzymes for drug delivery, probably due to their facile design. ${ }^{98}$ The attachment of bioactive moieties to carrier through enzyme-cleavable units triggers drug delivery from NP-based carriers. ${ }^{99}$ Similarly, the dispersion of inorganic NPs can be triggered by a hydrolase when the NPs are assembled by biomolecules presenting cleavable units. The rational design and development of a novel enzymeresponsive, doxorubicin peptide-coated magnetic silica NP was conjugated for selectively triggering intracellular delivery of doxorubicin into the tumor cells with specific protease enzyme expression. ${ }^{100}$ The highly efficient doxorubicin is released by the said ENP conjugate upon the specific enzyme interactions in vitro. Some hydrolase-responsive nanomaterials are already under clinical trials. ${ }^{98,101}$ The utilization of oxidoreductase is still in the proof-of-concept stage, and some pioneering examples of their utilization for drug delivery and diagnostics are being debated..$^{99}$ Other enzymes such as kinases and acetyltransferase have also been explored recently in this field. ${ }^{99}$

\section{Dendrimers as nanoparticle drug-carrier system}

Dendrimers are a unique class of repeatedly branched polymeric macromolecules with numerous arms extending from the center, resulting in a nearly perfect 3 -D geometric pattern. ${ }^{102}$ They comprise a series of branches around an inner core, the size and shape of which can be modulated as per the requirement. NPs based on dendrimers and oligonucleotidelinked dendrimers are expected to improve the therapeutic index of cytotoxic drugs by direct delivery to cancerous cells. ${ }^{103}$ There is also hope that delivering drugs by this approach could overcome drug resistance in tumor cells via bypassing Pgp pumps, ${ }^{103}$ which could serve as an attractive modality for drug delivery. ${ }^{104-106}$

The following properties are associated with dendrimers: ${ }^{102,107}$

1. Nanoscale sizes that have similar dimensions to important biobuilding blocks.

2. Numbers of terminal surface groups suitable for bioconjugation of drugs, signaling groups, targeting moieties, or biocompatibility groups.

3. Surfaces designed with functional groups to augment or resist transcellular, epithelial, or vascular biopermeability.

4. An interior void space may be used to encapsulate small-molecule drugs, metals, or imaging moieties and facilitates controlled release.

5. Positive biocompatibility patterns that are associated with lower generation of anionic or neutral polar terminal surface groups compared with higher-generation neutral apolar and cationic surface groups.

6. Non- or low immunogenicity associated with most dendrimer surfaces modified with small functional groups or PEG.

7. Surface groups that can be modified to optimize biodistribution, receptor-mediated targeting, therapy dosage, or controlled release of drug from the interior space.

8. Ability to arrange excretion mode from body. 
The possibility of a 2,2-bis(hydroxymethyl) propanoic acid-based dendritic scaffold as a delivery carrier for doxorubicin in vitro and in vivo has been explored. ${ }^{108}$ In an attempt to improve the efficacy of doxorubicin, photochemical internalization technology was utilized for site-specific delivery of membrane-impermeable macromolecules from endocytic vesicles into cytosol. ${ }^{109}$ Many researchers have also explored the feasibility of cisplatin incorporation in dendrimers. ${ }^{102,110,111}$ Polyamidoamine dendrimer complexes are reported to be used for DNA delivery to cell nucleus due to their high transfection efficiency and very low toxicity. ${ }^{102}$ They are favorite candidates to be used as the backbone of multitasking therapeutics because of their well-defined surface functionality, good water solubility, low polydispersity, and lack of immunogenicity. ${ }^{102}$ One of the early examples of polyamidoamine dendrimer having a fairly water-soluble nanoformulation has the ability to release cisplatin slowly in vitro. ${ }^{12}$ PEG-dendrimers are generally synthesized by the conjugation of PEG or polyethylene oxide chains to a multifunctional dendritic chain. ${ }^{113}$ They constitute a subclass of dendrimers that has attracted numerous researchers because of their prolonged blood circulation time, lower level of toxicity, and relatively lower accumulation in different organs. ${ }^{114}$

\section{Targeted drug delivery using gold nanoparticles}

GNPs are nanometer-sized colloidal suspensions. Multifunctional GNPs have been demonstrated to be highly stable and versatile scaffolds for drug delivery, due to their unique size coupled with their chemical and physical properties. ${ }^{115}$ The multiple receptor targeting, multimodality imaging, and multiple therapeutic entities holds the promise for a "magic gold bullet" against cancer. ${ }^{6}$ Different subtypes of GNPs such as gold nanospheres, nanorods, nanoshells, nanocages, and SERS NPs have been reported in literature based on their size, shape, and physical properties. ${ }^{6,116,117}$ Colloidal GNPs have great potential to overcome delivery limitations because of their biocompatibility, low toxicity, small size, and tunable surface functionalities. ${ }^{118}$ In cancer cell cultures, surface properties have been shown to regulate cellular uptake, intracellular release, and distribution in subcellular compartments. ${ }^{118}$ Modification of the surface properties of GNPs has potential to control accumulation in tumors, where drug payloads are released. GNPs functionalized with a thiolated PEG monolayer capped with a carboxylate group showed an improvement in platinum-based anticancer drugs, such as cisplatin, carboplatin, and oxaliplatin efficacy. ${ }^{119}$ Recently, GNPs conjugated with bovine serum albumin have been reported as one of the best vehicles for drug release. ${ }^{120} \mathrm{~A}$ modification of GNPs was reported, in which 11-mercapto-undecanoic acid-modified GNPs conjugated with chloroquine act as an efficient cancer therapy. ${ }^{121}$

\section{Quantum-dot nanocarrier systems for drug delivery}

QDs are spherical light-emitting NPs composed of a semiconductor material. They are a promising class of fluorescent probes for cancer screening from biological fluids, classification of tumor from biopsies, and for high-resolution biomolecular and cellular imaging. ${ }^{122,123}$ Initial results displayed by QDs synthesized by using reduced glutathione and TGA co-capped CdTe with good biological compatibility and high fluorescence intensity are quite encouraging for the treatment of colorectal cancer. ${ }^{124}$ Novel folate-conjugated carboxymethyl chitosan-ferroferric oxide-doped cadmium telluride QD NPs were developed with high drug-loading efficiency, low cytotoxicity, and favorable cell compatibility, and are promising candidates for carboxymethyl chitosan-based targeted drug delivery and cellular imaging. ${ }^{125}$ Codelivery of siRNA and chemotherapeutic agents has been developed recently to combat MDR in cancer therapy. Several QDs functionalized by $\beta$-cyclodextrin coupled to amino acids have been reported recently, some of which can be used to facilitate the delivery of siRNA. The intrinsic fluorescence of the QDs provides an opportunity to track the system by laser confocal microscopy. These multifunctional QDs are promising vehicles for the codelivery of nucleic acids and chemotherapeutics, and for real-time tracking during cancer treatment. ${ }^{126}$ Recent advances have led to multifunctional NP probes that are highly bright and stable under complex in vivo conditions. Polymer-encapsulated QDs are essentially nontoxic to cells and small animals, but their long term in vivo toxicity and degradation needs to be carefully studied. Nonetheless, bioconjugated QDs have raised new possibilities for ultrasensitive and multiplexed imaging of molecular targets in living cells and animal models. ${ }^{123}$ Moreover, magnetic NPs and QDs have been used effectively to achieve early diagnosis and recurrence prevention of lung cancer micrometastases in peripheral blood. ${ }^{127}$

\section{Solid-lipid nanoparticles as targeted drug-delivery system}

SLNs are physiological lipid-based NP systems that offer physical stability, protection of labile drugs from degradation, easy preparation, and low toxicity. ${ }^{57}$ SLNs have been developed as an alternative system to the existing traditional carriers, such as liposomes and polymeric NPs. They are new-generation submicron-sized lipid emulsions where 
the liquid lipid has been substituted by a solid lipid. SLNs offer unique properties, such as small size, large surface area, high drug loading, and the interaction of phases at the interfaces, and are attractive for their potential to improve performance of pharmaceuticals, neutraceuticals, and other materials. ${ }^{128}$ Recently, several studies reported the use of SLNs as tumor-targeted drug-delivery systems. ${ }^{42,57,129,130}$ SLNs loaded with doxorubicin were studied in Pgp-overexpressing MCF-7/ADR cell lines. ${ }^{57}$ Efficiently enhanced apoptotic cell death via higher accumulation of doxorubicin by SLNs in cancer cells was also reported. ${ }^{57}$ Targeted delivery of a potent anticancer compound, namely curcumin, incorporated with transferrin-mediated SLNs has also been reported in MCF-7 breast cancer cells. ${ }^{42}$ More recently, high-pressure homogenized emodin-loaded SLNs gave positive antitumor activity in vitro. ${ }^{129}$ Moreover, cationic lipid-bound oligonucleotide-loaded SLNs are also reported as a potential new approach for carrying antimiRNA inhibitors for cancer therapy. ${ }^{130}$

\section{Polymeric nanoparticles as targeted drug-delivery system}

PNPs offer a promising means of targeted drug delivery of chemotherapeutic drugs with enhanced efficacy, reduced toxicity, controlled and long-term release rates, prolonged bioactivity, increased patient compliance due to less administration frequency, and the ability to codeliver multiple drugs with synergistic effects at the same site. ${ }^{131}$ A protective covering provided by the PNPs to chemotherapeutic drugs limits their interaction with healthy cells. ${ }^{131}$ PNPs are available in different types, such as nanospheres, in which the particles' entire mass is solid and molecules may be adsorbed at the sphere surface or encapsulated within the particle matrix, and nanocapsules, in which the entrapped substances are confined to a cavity consisting of a liquid core (either oil or water) surrounded by a solid material shell. ${ }^{132}$ The properties of PNPs need to be optimized depending on the particular application. In order to achieve the properties of interest, the mode of preparation plays a vital role. ${ }^{132}$

There is scope for many variations in polymer chemistry where PNPs can be easily manipulated without loss of their desired physical, chemical, and biological properties. ${ }^{133}$ PNPs are often produced by pairing PEG with the polymer of NPs. PEG inhibits binding of plasma proteins to the surface of PNPs, which provides prolonged systemic circulation time, prevents recognition by the reticuloendothelial system, ${ }^{134}$ and an EPR effect in different types of tumors. ${ }^{131} \mathrm{Hu}$ et al reported prolonged circulation and enhanced anticancer potential of one anticancer agent, endostar, a novel recombinant human endostatin, which was approved by the Chinese State Food and Drug Administration in 2005 with PNPs (PEG-PLGA nanoparticles). ${ }^{135}$

PNPs coupled with ligands and aptamers have been reported as a way to actively target cancerous cells that further induce receptor-mediated endocytosis for intracellular delivery. A novel injectable formulation of an anticancer drug, sirolimus, using PNP has been reported as an attractive new therapeutic approach for cancer therapy that offers improved pharmacokinetic features and gets readily dispersed in physiological media without any surfactants or cosolvents. PNP-sirolimus effectively inhibited tumor cell proliferation and tumor mass growth and enhanced radiation-induced cell death by inhibition of the mammalian target of rapamycin (mTOR), mTOR pathway and activation of autophagy. ${ }^{136}$

Anticancer drugs loaded in PLGA-lecithin-PEG NPs and functionalized with AS1411 antinucleolin aptamers have been reported as having high encapsulation efficiency and superior sustained drug release for differential targeted drug delivery in cancer treatment. ${ }^{137}$ Aptamer-functionalized PEG-PLGA nanoparticles have been reported with enhanced delivery of paclitaxel as a therapeutic application in the treatment of gliomas. ${ }^{138}$ Targeted delivery of an anticancer agent, cisplatin, against prostate cancer cells by aptamer-functionalized Pt(IV) prodrug-PLGA-PEG NPs have been also reported with higher efficiency compared with free cisplatin. ${ }^{139}$ Enhanced cellular uptake of folic acid-conjugated PLGA-PEG nanoparticles loaded with vincristine sulfate have been reported to contain significantly higher cellular uptake in the folic acid receptor over expressed MCF-7 cells, compared to PLGA-mPEG NPs without folic acid modification. ${ }^{140}$ A novel redoxsensitive biodegradable polymer with "trimethyl-locked" benzoquinone has been reported for the preparation of paclitaxel-incorporated NPs to release paclitaxel in response to chemically triggered reduction. ${ }^{141}$ With further development in these technologies and other methods of triggering and targeting, polymer nanomaterials will provide improved cancer treatment methods.

\section{Use of NPs in cancer treatment via thermal ablation}

There is a great demand for minimally invasive options to conventional surgery like thermal ablative technologies for the treatment of cancer. ${ }^{142}$ Radio-frequency, microwave, and laser-based hyperthermia allow less invasive treatments but still require insertion of a probe into the lesion to be treated. ${ }^{143}$ Recent advances in nanoscale materials have 
provided a potentially noninvasive means of heating cells to cytotoxic levels. Temperatures above $42^{\circ} \mathrm{C}$ induce cell death in some tissues. Cells of any nature (cancerous or normal) heated to temperatures in the range of $41^{\circ} \mathrm{C}-47^{\circ} \mathrm{C}$ begin to show signs of apoptosis, ${ }^{144}$ while temperatures above $50^{\circ} \mathrm{C}$ are associated with less apoptosis and more necrosis. ${ }^{145}$ Hyperthermic adjuvant chemotherapy plays an increasing role in multimodality cancer treatment. ${ }^{146}$ It has been suggested that minimal tissue hyperthermia increases the blood flow and yields higher concentrations of chemotherapeutic agents, which results in enhanced therapeutic effect. Similar to chemotherapy, radiotherapy is also more effective using hyperthermia as an adjunct treatment. ${ }^{145}$ Targeted hyperthermia is achieved by using nanoscale metallic particles that convert electromagnetic energy into heat. Metal NPs exemplify the potential for application in targeted hyperthermic therapy, specifically iron oxide NPs, gold-silica nanoshells, solid-gold NPs and CNTs. ${ }^{145,147}$ Iron oxide NPs have been used as both diagnostic and therapeutic nanoscale materials to treat deep tissue tumors. With certain drawbacks, iron NPs continue to be actively investigated because of their minimal toxicity and potential for rapid heating. ${ }^{148}$ GNPs could be heated with shortwave radio-frequency fields. By labeling GNPs with antibodies against particular cancer cells, higher concentrations of GNPs could be achieved. Once the particles are internalized, radio-frequency fields applied to cells result in localized heat and killing of cancer cells. ${ }^{145}$

CNTs are capable of being targeted and delivered to specific cells either through direct covalent functionalization or through noncovalent wrapping of targeting moieties. The absorption characteristics of CNTs have been utilized as hyperthermic enhancers using near-infrared absorptions. ${ }^{149}$ CNTs significantly absorb intense heat release under capacitively coupled radio-frequency fields, similar to GNPs. ${ }^{150}$ QDs also have great potential in photodynamic therapy, where they act as either photosensitizers themselves or as a carrier. ${ }^{151,152}$ Although nanotechnology is a relatively new field of investigation, using targeted NPs in the hyperthermic treatment of cancer cells is expected to be a viable option for cancer treatment. ${ }^{145}$ Moreover, these days application of nanotechnology for laser thermal-based killing of cancerous cells, targeted with absorbing NPs, is becoming an extensive area of research. ${ }^{153}$

\section{Use of nanotechnology in cancer treatment via gene therapy}

Gene therapy can be defined as the transfer of genetic material to the cells of an individual, in order to ensure a targeted molecular intervention and achieve a higher level of specific action than conventional cytotoxic chemotherapy. Recently, the gene-silencing technique has gained much popularity. There are three major nucleic acid-based genesilencing molecules viz antisense oligodeoxyribonucleic acids, siRNA, and micro RNA. Despite so much promise of gene therapy, a number of difficulties remain to be conquered; the most important is the need for more efficient gene-delivery systems. The success of a gene therapy largely depends upon the activity induced by the target genes and the efficiency of gene delivery resulting from the combined effects of the delivery vector and the applied delivery route. ${ }^{154}$ Various NPs have been investigated for gene delivery, including GNPs, ${ }^{155}$ silver NPs, ${ }^{156} \mathrm{CNTs},{ }^{157}$ liposomes, ${ }^{158}$ polymersomes, ${ }^{159}$ and polyplexes. Use of NPs enables targeting of tumor tissue through the EPR effect in gene therapy. Kim et al reported a mannosylated chitosan NP-mediated cytokine gene-delivery system for cancer immunotherapy. ${ }^{160}$ Recently, thiolated chitosan NPs as a delivery system for antisense therapy has also been reported in T47D breast cancer cells. ${ }^{161}$ A nanosized immune liposome-based delivery complex was also reported, which preferentially targets and delivers molecules useful in gene medicine, including plasmid DNA and antisense oligonucleotides to tumor cells. ${ }^{162}$ This tumor-targeting NP delivery vehicle can also deliver siRNA to both primary and metastatic cells.

A gene-delivery vehicle, nonviral vector DOTAP: cholesterol has been suggested as an effective systemic genedelivery vector that efficiently delivers tumor-suppressor genes to disseminated lung tumors. ${ }^{163}$ A promising role of novel nonviral gene carrier heparin-polyethyleneimine (HPEI) NP-mediated ms-T34 A in C-26 colon carcinoma therapy was also reported. ${ }^{164}$ PEI-derived NPs such as poly ( $\varepsilon$-caprolactone)-pluronic-poly( $\varepsilon$-caprolactone)-grafted PEI (PCFC-g-PEI), folic acid-PCFC-isophorone diidocyanatePEI and HPEI are reported as gene-therapy delivery systems for renal cell carcinoma. ${ }^{165}$ It has been reported in the literature that QDs may also function as gene-delivery vehicles if modified with lipofectamine, ${ }^{166,167}$ encapsulated in poly(maleic-anhydride-alt-1-decene), surface-modified with dimethylamino propylamine and poly(maleic-anhydride-alt1-decene) coated. QDs have been reported as siRNA delivery vehicles and exhibit up to a 20 -fold increase in silencing effect and a sixfold decrease in toxicity compared with other common delivery agents. ${ }^{167}$

Gene delivery could also be achieved by the use of CNTs. ${ }^{2}$ They are a good nonviral vector for gene therapy, 
and can cross the cell membrane by an endocytosis process. ${ }^{168}$ CNTs are promising vectors for gene and protein, for which they have shown much greater fluorescent activity of protein and DNA when conjugated to singlewalled NTs. ${ }^{169}$ The delivery of siRNA for treatment of tumor cells using functionalized MWCNTs and liposomes showed that the siRNA delivered via MWCNTs achieved significant inhibition of tumor growth. ${ }^{170}$ Dendrimers have also been reported to enter tumors and carry either chemotherapeutic agents or genetic therapeutics. They could be conjugated to fluorochromes and possess the ability to enter into cells. They can then be detected within the cell in a manner compatible with sensing apparatus for evaluation of physiologic changes. ${ }^{171}$ DNA-assembled polyamidoamine dendrimer clusters for cancer cell-specific targeting were also reported. Dendrimer-5-fluorouracil (5FU) conjugates were prepared by acetylation, and upon hydrolysis release free 5FU, thus minimizing the toxicity of 5FU. ${ }^{172}$ In earlier studies, researchers have shown that cisplatin encapsulated in dendrimer polymers has increased efficacy and is comparatively less toxic. ${ }^{173}$ Novel genesilencing strategy in gene therapy involving the use of siRNA can be conjugated to phospholipid-functionalized SWNTs using a cleavable disulfide linker, resulting in efficient gene silencing and subsequent death of the targeted cell. ${ }^{149}$ Amino-functionalized MWNT-siRNA complexes have shown successful suppression of tumor and prolonged survival in lung tumor in animal model. ${ }^{170} \mathrm{CNTs}$ cationically functionalized with PEI have been shown to be capable of complexing with siRNA and significantly increasing silencing activity and cytotoxicity. ${ }^{174}$ A highly efficient, low-toxic, and specifically targeting gene-delivery vector (H1) was also reported. ${ }^{175}$ Peritumoral injection of H1/pIL-2 NPs displayed effective antitumor potential. Researchers have derived PEI-coated virus-like particles from an adeno-associated virus type 2 delivery system for potential therapy of breast cancer. ${ }^{176}$

\section{Nanotechnology-based approaches in cancer diagnostics}

One of the major reasons behind low survival rates among cancer patients is the failure to detect the disease at an early stage. Modern imaging technologies have made enormous advances. However, the effective early detection of precancerous and neoplastic lesions remains an elusive goal. The challenge is to find a test that can detect clinically apparent cancer cases at an early stage, long before the symptoms become visible. A variety of highly integrated nanotechnology platforms to diagnose cancer hold considerable promise. NP probes, nanocantilever, nanowire, and nanotube arrays are expected to solve the problem of early detection of different types of cancer. ${ }^{13}$ Nanomaterials possess long-term stability and enable the design of powerful bioassays for simultaneous measurements of multiple markers of a disease. ${ }^{177}$ Nanomaterial-based probes involve the use of nanotechnology to meet the demands of in vitro diagnostics for increased sensitivity and rapid detection from complex environmental systems. ${ }^{178}$ NPs labeled in vivo signaling moiety offer better molecularly targeted specificity than conventional imaging techniques. Various combinations of multifunctional NPs have been established with imaging agents like radioisotopes, lanthanides, or fluorophores. ${ }^{179}$ Hopefully, nanotechnology could lead to a paradigm shift in cancer detection, diagnosis, and therapy.

Some of the existing technologies for cancer imaging include noninvasive imaging techniques, such as computed tomography (CT), magnetic resonance imaging (MRI), positron emission tomography (PET), ultrasound scans, single-photon emission CT, optical imaging, and macroscopically visualizing tumors. ${ }^{180}$ Unfortunately, most of these imaging techniques are somewhat limited to detecting abnormalities at the microscopic level. It is possible, however, to combine existing optical imaging technologies with sophisticated NP-based optical contrast agents for highresolution in vivo cancer imaging. Recently, this strategy has been successfully demonstrated for detecting tumors. ${ }^{181}$ However, developing reliable early detection approaches from serum, other biological fluids, or any sample obtained through minimal or noninvasive procedures remains of supreme importance.

\section{Various nanotechnology platforms for the detection of cancer}

\section{Approaches for the in vivo detection} and monitoring of cancer biomarkers

To identify malignancies based on their molecular expression profiles, all imaging technologies require contrast agents, comprising a signal-amplifying material conjugated to a molecular recognition and targeting agent such as an antibody. $^{13}$

\section{In vitro detection}

Various novel assemblies of NP systems have been reported as nanoprobes for the early detection of cancer. Nanomaterials such as NPs, nanowires, nanotubes and nanodevices have been explored as ultrasensitive probes to 
detect cancer biomarkers. ${ }^{178} \mathrm{NP}$ probes with molecularly targeted recognition agents might provide information on the presence, relative abundance, and distribution of cancer signatures and markers associated with the tumor microenvironment. ${ }^{13}$ Because of their unique properties, QDs are one of the well-established NPs that cover applications such as cellular imaging, immunoassays, in vivo imaging, and sensing. ${ }^{182,183}$ QD-based microfluidic protein chip detection and optically addressed fluorescence resonance energy transfer (FRET) probes are being used in signal transduction to design the detection systems for nucleic acids, proteins, peptides, and small molecules. ${ }^{184,185}$ The increased number of acceptors linked to QDs can significantly amplify the signal of the target through enhanced energy-transfer efficiency. This ultrasensitive nanoprobe based on the FRET system had the capability to detect low concentrations of DNA, which have great potential to diagnose DNA mutations of tumor cells in clinical samples. ${ }^{178}$ Methylation-specific QD-FRET offers great promise for its translational use in early cancer diagnosis, prognostic assessment of tumor behavior, and monitoring response to therapeutic agents in clinical samples. ${ }^{186}$ QD-based bioluminescence resonance energy transfer (BRET) conjugated to bioluminescent proteins uses biochemical energy to excite fluorophores and offers additional advantages over FRET system for various bioanalyses. ${ }^{187}$ A nanoplatform of protease probing based on the BRET system was designed to detect protease activity in complex biological samples. ${ }^{188}$ The sensitivity of this technology has great clinical value to cancer diagnosis and monitoring.

Nanophotonic methods also possess important applications in bioanalyses and spectroscopy using plasmonic NPs and can monitor the molecular binding events and changes in molecular conformation with exquisite sensitivity. ${ }^{178}$ The said nanoprobe could be used to follow cell-signaling pathways at the single-molecule level in the living cells, which was not possible by conventional single-moleculeimaging techniques. ${ }^{189,190}$ The multiplex protein detection of potential cancer markers was achieved using highly sensitive giant magnetoresistive sensors capable of detecting even ten magnetic nanotags. ${ }^{191}$ Recently, a magnetic NP-based method has been reported, which is an alternate to PCR methods and enzyme-linked immunosorbent assays for in vitro detection of viruses and circulating tumor cells in biological samples. ${ }^{178}$ Although this technique is fast, sensitive, and suitable in complex biological media, it could be broadly applied to detect different biomarkers and biological species with increased sensitivity and specificity, and might become a truly portable, easy-to-use and low-cost device for point-of-care in vitro diagnostics of different types of cancer in future. ${ }^{178}$

\section{Ex vivo detection}

NPs have also shown promise for the ex vivo detection of cancer biomarkers. ${ }^{13}$ The ex vivo detection technique offers the potential advantages of readily identifying the conjugate markers, yielding specific information on their tissue distribution, introducing new protocols that include cell surface, endocellular, and microenvironmental antigens in the same test. Gold-nanoshell-based immunoassays have been developed for the detection of various analytes of subnanogramper-milliliter quantities. ${ }^{192}$ Fluorescent NPs have been used for an ultrasensitive DNA-detection system, ${ }^{193}$ and QD bioconjugates with targeting antibodies have been used to recognize molecular signatures, including ERBB2. ${ }^{194}$ In one study, fluorophore-laden silica beads were used for the optical identification of leukemia cells in blood samples. ${ }^{195}$

\section{Nanotubes, nanowires, and nanodevices}

Nanocantilevers, nanowires, and nanotubes also have many applications in biology and medicine because of their unique structures and properties. Use of these devices facilitates the transition from single-biomarker to multiplebiomarker cancer diagnostics, prognostics, and treatment. Nanocantilevers are in the class of nanotechnology-based methods that deflect and change resonant frequencies as a result of affinity-binding of biomarker proteins or nucleic acid hybridization events occurring on their free surfaces. ${ }^{196}$ The breakthrough potential afforded by nanocantilevers resides in their extraordinary multiplexing capability. ${ }^{197} \mathrm{In}$ one study, Majumdar used microcantilevers to detect SNPs in a 10-mer DNA target oligonucleotide without using extrinsic fluorescent or radioactive labeling. ${ }^{198}$

Devices based on nanowires are emerging as a powerful and general platform for ultrasensitive, direct electrical detection of biological and chemical species. Nanowire and nanotube arrays might contain several thousand sensors on a single chip, therefore offering even greater multiplexing advantages. ${ }^{13}$ A silicon (Si) nanowire field-effect device was developed, in which distinct nanowires and surface receptors are incorporated into arrays. ${ }^{199}$ The capability of Si-nanowire probes for multiplexed real-time monitoring of protein markers with high sensitivity and selectivity in clinically relevant samples opens up substantial possibilities for the diagnosis and treatment of cancer. ${ }^{200}$ SWCNTs exhibit distinct electrical and spectroscopic properties such as photo luminance in the near-infrared range and strong 
resonant Raman scattering. ${ }^{201}$ They promise great potential applications in biological detection and imaging because of their unique Raman properties. ${ }^{202}$

\section{Multifunctional nanomaterials}

Combined uses of multiple-platform diagnostic nanotechnologies are emerging day by day. Multifunctional nanomaterials are highly sensitive, stable, detectable, biocompatible, and targetable. ${ }^{178}$ The development of multiple integrated nanoprobe systems includes metals, oxides, polymers, enzymes, or other components to give the system, required functionality, and specificity. ${ }^{115,178}$ The combination of QDs and iron oxide NPs can create a single NP probe that may lead to clinically useful measurements and images of cancer at molecular levels both in vitro and in vivo. ${ }^{100}$ The combination of metallic NPs and magnetic NPs is another type of multifunctional NP, which is likely to lead to new applications in biomedicine because metallic NPs possess intrinsic properties and functions as optical-contrast agents and probes. ${ }^{178}$ Park et al reported the simultaneous dual-mode imaging (MRI and fluorescence imaging) in vitro and in vivo, using hybrid nanostructures containing magnetic NPs and QDs. ${ }^{203}$ A polymeric multifunctional optical nanoprobe platform was developed and successfully demonstrated the applications of multifunctional nanomaterials, such as real-time oxygen sensors, in situ optical probes, magnetic $\mathrm{pH}$ sensors, and stimuli-responsive magnetic optical probes. ${ }^{204}$

\section{Recent developments in nanotechnology- based cancer detection}

A cyclic RGD peptide-conjugated type II CdTe/CdS QD formulation was reported for targeting and imaging of pancreatic tumor vasculature in live animals. ${ }^{205}$ Lanthanoid trivalent ion-based luminescence agents have been reported as optical probes that have more potential than QDs. ${ }^{206,207}$ The efficacy of europium-catalyzed SWCNT was reported as a novel excellent visible candidate probe for targeted cellular imaging. ${ }^{207}$ Lewis et al reported noble metal NPs coated with cerium and luminescent europium complexes for bioimaging and potential biodelivery applications. ${ }^{208}$

Theranostic MRI is now receiving growing interest in imaging-guided drug delivery, monitoring treatment, and personalized administration. ${ }^{209}$ Recently, an SWCNT-AuPEG nanocomposite was reported as an interesting optical theranostic probe for cancer imaging and therapy. ${ }^{210}$ Luminescence-quenched shell cross-linked NPs as photonic nanoprobes are reported to detect a protease, which is a viable marker for cancer imaging in vivo. ${ }^{211}$ Polysorbate 80 -coated temozolomide-loaded PLGA-based superparamagnetic NPs have been characterized as drug carriers and good MRI contrast agents for diagnosing malignant brain glioma. ${ }^{212} \mathrm{~A}$ multifunctional nanoprobe is prepared by functionalizing $\mathrm{SnO}_{2}$ NPs with both folic acid as targeting moiety and a gene probe to inhibit or recognize intracellular miRNA levels for target cell-specific imaging and in situ detection of intracellular miRNA. ${ }^{213}$ A sensitive and selective sensor for detecting colon cancer based on NP covalent modified antihuman epithelial cell adhesion-molecule antibody was also developed. ${ }^{214}$

Recently, a highly efficient multifunctional nanoplatform, multicolor luminescent $\mathrm{NaYF}_{4}: \mathrm{Yb}^{3+}, \mathrm{Er}^{3+}$ upconversion NPs were reported by Liu et al, ${ }^{215}$ which could be utilized in image-guided cancer photodynamic therapy. For the first time, Wang et al reported a synthesis of biocompatible triplex Ag@SiO $@ \mathrm{STiO}_{2}$ core-shell NPs that possessed a combined capacity for fast and multiplexed fluorescencesurface-enhanced Raman scattering F-SERS labeling for imaging as well as drug loading for cancer therapy. ${ }^{210}$ In one study, optimized magnetic-particle imaging tracers using iron oxide NPs traced significant signal intensity and better spatial resolution compared with commercial NPs developed for MRI. ${ }^{216}$ High-contrast imaging can be achieved by gold nanorods with targeted tumor-growth-factor receptors as compared to nontargeted gold nanorods. This can facilitate imaging and demarcating tumor margins during surgical resection. ${ }^{217}$ In one study, hyaluronan-coated superparamagnetic iron oxide NPs with high magnetic relaxivity were reported as a promising system with enhanced uptake and enabled MRI of cancer cells for targeted drug delivery. ${ }^{218}$

\section{Future perspectives}

Nanotechnology is a rapidly developing field that has given new hope in the treatment of various diseases. Early detection and treatment of cancer remains a challenge to the scientific community. Moreover, different strategies have been explored in recent years for cancer detection and therapy. Application of nanotechnology in cancer treatment seems to solve these limitations, which has given new hope to humanity. Specific targeting of cancer cells was also the major challenge faced by conventional therapeutic approaches of cancer treatment. Recently, various NP-based drug-delivery systems such as liposomes, dendrimers, diamondoids, QDs, viral NPs, and CNTs have shown encouraging results in cancer therapy. Properties like prolonged existence in systemic circulation, enhanced drug localization, and their efficacy make the NP-based model an excellent one. One of the major challenges in cancer treatment, ie, MDR, can also be overcome by these NP formulations. In 
the light of our review, we expect that in future, different NP formulations would serve as "Trojan horses" in the field of cancer diagnostics and its treatment. Hereby, we find it pertinent to highlight that toxicity and immune-system induction should be given due consideration before finalizing the use of any NP formulation for diagnostic and treatment purposes.

\section{Acknowledgments}

The authors gratefully acknowledge King Fahd Medical Research Center, King Abdulaziz University, Jeddah, Saudi Arabia, for providing the research platform and IT facility.

\section{Disclosure}

The authors report no conflicts of interest in this work.

\section{References}

1. Feinberg AP, Ohlsson R, Henikoff S. The epigenetic progenitor origin of human cancer. Nat Rev Genet. 2006;7(1):21-33.

2. Madani SY, Naderi N, Dissanayake O, Tan A, Seifalian AM. A new era of cancer treatment: carbon nanotubes as drug delivery tools. Int $J$ Nanomedicine. 2011;6:2963-2979.

3. Ferlay J, Shin HR, Bray F, Forman D, Mathers C, Parkin DM. Estimates of worldwide burden of cancer in 2008: GLOBOCAN 2008. Int $J$ Cancer. 2010;127(12):2893-2917.

4. American Cancer Society. Cancer Facts and Figures 2011. Atlanta, GA: American Cancer Society, 2011.

5. Choi YE, Kwak JW, Park JW. Nanotechnology for early cancer detection. Sensors. 2010;10(1):428-455.

6. Cai W, Gao T, Hong H, Sun J. Applications of gold nanoparticles in cancer nanotechnology. Nanotechnol Sci Appl. 2008;1:11.

7. Jean-Mary F. Spectroscopic and Microscopic Studies of Aggregated Molecules Coated onto Nanomaterials. Ann Arbor: ProQuest; 2006.

8. Elsersawi A. World of Nanobioengineering: Potential Big Ideas for the Future. Bloomington: AuthorHouse; 2010.

9. Grodzinski P, Silver M, Molnar LK. Nanotechnology for cancer diagnostics: promises and challenges. Expert Rev Mol Diagn. 2006;6(3):307-318.

10. Sahoo SK, Parveen S, Panda JJ. The present and future of nanotechnology in human health care. Nanomedicine. 2007;3(1):20-31.

11. Kircher MF, Mahmood U, King RS, Weissleder R, Josephson L. A multimodal nanoparticle for preoperative magnetic resonance imaging and intraoperative optical brain tumor delineation. Cancer Res. 2003;63(23):8122-8125.

12. Nam JM, Stoeva SI, Mirkin CA. Bio-bar-code-based DNA detection with PCR-like sensitivity. J Am Chem Soc. 2004;126(19):5932-5933.

13. Ferrari M. Cancer nanotechnology: opportunities and challenges. Nat Rev Cancer. 2005;5(3):161-171.

14. Neuwelt EA, Várallyay P, Bagó AG, Muldoon LL, Nesbit G, Nixon R. Imaging of iron oxide nanoparticles by MR and light microscopy in patients with malignant brain tumours. Neuropathol Appl Neurobiol. 2004;30(5):456-471.

15. Jamieson T, Bakhshi R, Petrova D, Pocock R, Imani M, Seifalian AM. Biological applications of quantum dots. Biomaterials. 2007;28(31): 4717-4732.

16. Cai W, Chen X. Multimodality molecular imaging of tumor angiogenesis. J Nucl Med. 2008;49 Suppl 2:113S-128S.

17. Sikora K. The impact of future technology on cancer care. Clin Med. 2002;2(6):560-568.

18. Singh OP, Nehru RM. Nanotechnology and cancer treatment. Asian $J$ Exp Sci. 2008;22(2):6.
19. Chidambaram M, Manavalan R, Kathiresan K. Nanotherapeutics to overcome conventional cancer chemotherapy limitations. JPharm Pharm Sci. 2011;14(1):67-77.

20. Sinha R, Kim GJ, Nie S, Shin DM. Nanotechnology in cancer therapeutics: bioconjugated nanoparticles for drug delivery. Mol Cancer Ther. 2006;5(8):1909-1917.

21. Ranganathan R, Madanmohan S, Kesavan A, et al. Nanomedicine: towards development of patient-friendly drug-delivery systems for oncological applications. Int J Nanomedicine. 2012;7:1043-1060.

22. Cho K, Wang X, Nie S, Chen ZG, Shin DM. Therapeutic nanoparticles for drug delivery in cancer. Clin Cancer Res. 2008;14(5):1310-1316.

23. Gelperina S, Kisich K, Iseman MD, Heifets L. The potential advantages of nanoparticle drug delivery systems in chemotherapy of tuberculosis. Am J Respir Crit Care Med. 2005;172(12):1487-1490.

24. Ghanbari H, de Mel A, Seifalian AM. Cardiovascular application of polyhedral oligomeric silsesquioxane nanomaterials: a glimpse into prospective horizons. Int J Nanomedicine. 2011;6:775-786.

25. Haley B, Frenkel E. Nanoparticles for drug delivery in cancer treatment. Urol Oncol. 2008;26(1):57-64.

26. Byrne JD, Betancourt T, Brannon-Peppas L. Active targeting schemes for nanoparticle systems in cancer therapeutics. Adv Drug Deliv Rev. 2008;60(15):1615-1626.

27. Hahn MA, Singh AK, Sharma P, Brown SC, Moudgil BM. Nanoparticles as contrast agents for in-vivo bioimaging: current status and future perspectives. Anal Bioanal Chem. 2011;399(1):3-27.

28. Naga AP, Siddiqui A. Nanomedical platform for drug delivery. J Nanomed Nanotechnol. 2011;2:122.

29. Brannon-Peppas L, Blanchette JO. Nanoparticle and targeted systems for cancer therapy. Adv Drug Deliv Rev. 2004;56(11):1649-1659.

30. Yu MK, Park J, Jon S. Targeting strategies for multifunctional nanoparticles in cancer imaging and therapy. Theranostics. 2012;2(1):3-44.

31. Dong X, Mumper RJ. Nanomedicinal strategies to treat multidrugresistant tumors: current progress. Nanomedicine (Lond). 2010; 5(4):597-615.

32. Kontermann RE. Immunoliposomes for cancer therapy. Curr Opin Mol Ther. 2006;8(1):39-45.

33. Alexis F, Basto P, Levy-Nissenbaum E, et al. HER-2-targeted nanoparticle-affibody bioconjugates for cancer therapy. Chem Med Chem. 2008;3(12):1839-1843.

34. Puri A, Kramer-Marek G, Campbell-Massa R, et al. HER2-specific affibody-conjugated thermosensitive liposomes (Affisomes) for improved delivery of anticancer agents. J Liposome Res. 2008;18(4): 293-307.

35. Lavasanifar A, Samuel J, Kwon GS. Poly(ethylene oxide)-block-poly (L-amino acid) micelles for drug delivery. Adv Drug Deliv Rev. 2002;54(2): 169-190.

36. Gullotti E, Yeo Y. Extracellularly activated nanocarriers: a new paradigm of tumor targeted drug delivery. Mol Pharm. 2009;6(4):1041-1051.

37. Lammers T, Hennink WE, Storm G. Tumour-targeted nanomedicines: principles and practice. Br J Cancer. 2008;99(3):392-397.

38. Allen TM, Cullis PR. Drug delivery systems: entering the mainstream. Science. 2004;303(5665):1818-1822.

39. Pauwels EKJ, Kairemo K, Erba P, Bergstrom K. Nanoparticles in cancer. Curr Radiopharm. 2010;1(1):30-36.

40. Zhang C, Zhao L, Dong Y, Zhang X, Lin J, Chen Z. Folate-mediated poly(3-hydroxybutyrate-co-3-hydroxyoctanoate) nanoparticles for targeting drug delivery. Eur J Pharm Biopharm. 2010;76(1): $10-16$.

41. Canal F, Vicent MJ, Pasut G, Schiavon O. Relevance of folic acid/ polymer ratio in targeted PEG-epirubicin conjugates. J Control Release. 2010;146(3):388-399.

42. Mulik RS, Mönkkönen J, Juvonen RO, Mahadik KR, Paradkar AR. Transferrin mediated solid lipid nanoparticles containing curcumin: enhanced in vitro anticancer activity by induction of apoptosis. Int $J$ Pharm. 2010;398(1-2):190-203.

43. Ma Y, Nolte RJ, Cornelissen JJ. Virus-based nanocarriers for drug delivery. Adv Drug Deliv Rev. 2012;64(9):811-825. 
44. Duncan R, Vicent MJ, Greco F, Nicholson RI. Polymer-drug conjugates: towards a novel approach for the treatment of endrocine-related cancer. Endocr Relat Cancer. 2005;12 Suppl 1:S189-S199.

45. Fang J, Nakamura H, Maeda H. The EPR effect: unique features of tumor blood vessels for drug delivery, factors involved, and limitations and augmentation of the effect. Adv Drug Deliv Rev. 2011;63(3):136-151.

46. Stylianopoulos T, Wong C, Bawendi MG, Jain RK, Fukumura D. Multistage nanoparticles for improved delivery into tumor tissue. Methods Enzymol. 2012;508:109-130.

47. Petrelli F, Borgonovo K, Barni S. Targeted delivery for breast cancer therapy: the history of nanoparticle-albumin-bound paclitaxel. Expert Opin Pharmacother. 2010;11(8):1413-1432.

48. Gindy ME, Prud'homme RK. Multifunctional nanoparticles for imaging, delivery and targeting in cancer therapy. Expert Opin Drug Deliv. 2009;6(8):865-878.

49. Garg A, Tisdale AW, Haidari E, Kokkoli E. Targeting colon cancer cells using PEGylated liposomes modified with a fibronectin-mimetic peptide. Int J Pharm. 2009;366(1-2):201-210.

50. Ruoslahti E, Bhatia SN, Sailor MJ. Targeting of drugs and nanoparticles to tumors. J Cell Biol. 2010;188(6):759-768.

51. Suri SS, Fenniri H, Singh B. Nanotechnology-based drug delivery systems. J Occup Med Toxicol. 2007;2:16-16.

52. Peng XH, Qian X, Mao H, et al. Targeted magnetic iron oxide nanoparticles for tumor imaging and therapy. Int J Nanomedicine. 2008;3(3):311-321.

53. MacEwan SR, Callahan DJ, Chilkoti A. Stimulus-responsive macromolecules and nanoparticles for cancer drug delivery. Nanomedicine (Lond). 2010;5(5):793-806.

54. Jin C, Bai L, Wu H, Liu J, Guo G, Chen J. Paclitaxel-loaded poly(D,Llactide-co-glycolide) nanoparticles for radiotherapy in hypoxic human tumor cells in vitro. Cancer Biol Ther. 2008;7(6):911-916.

55. Torchilin V. Tumor delivery of macromolecular drugs based on the EPR effect. Adv Drug Deliv Rev. 2011;63(3):131-135.

56. Choi CHJ, Alabi CA, Webster P, Davis ME. Mechanism of active targeting in solid tumors with transferrin-containing gold nanoparticles. Proc Natl Acad Sci U S A. 2010;107(3):1235-1240.

57. Kang KW, Chun MK, Kim O, et al. Doxorubicin-loaded solid lipid nanoparticles to overcome multidrug resistance in cancer therapy. Nanomedicine. 2010;6(2):210-213.

58. Chen AM, Zhang M, Wei D, et al. Co-delivery of doxorubicin and Bcl-2 siRNA by mesoporous silica nanoparticles enhances the efficacy of chemotherapy in multidrug-resistant cancer cells. Small. 2009;5(23):2673-2677.

59. Song XR, Cai Z, Zheng Y, et al. Reversion of multidrug resistance by co-encapsulation of vincristine and verapamil in PLGA nanoparticles. Eur J Pharm Sci. 2009;37(3-4):300-305.

60. Koziara JM, Whisman TR, Tseng MT, Mumper RJ. In-vivo efficacy of novel paclitaxel nanoparticles in paclitaxel-resistant human colorectal tumors. J Control Release. 2006;112(3):312-319.

61. Zhang Y, Tang L, Sun L, et al. A novel paclitaxel-loaded poly(epsiloncaprolactone)/Poloxamer 188 blend nanoparticle overcoming multidrug resistance for cancer treatment. Acta Biomater. 2010;6(6): 2045-2052.

62. Miele E, Spinelli GP, Miele E, Tomao F, Tomao S. Albumin-bound formulation of paclitaxel (Abraxane ABI-007) in the treatment of breast cancer. Int J Nanomedicine. 2009;4:99-105.

63. Zhao D, Zhao X, Zu Y, et al. Preparation, characterization, and in vitro targeted delivery of folate-decorated paclitaxel-loaded bovine serum albumin nanoparticles. Int J Nanomedicine. 2010;5:669-677.

64. Sharma A, Sharma US. Liposomes in drug delivery: progress and limitations. Int J Pharm. 1997;154(2):123-140.

65. Fenske DB, Chonn A, Cullis PR. Liposomal nanomedicines: an emerging field. Toxicol Pathol. 2008;36(1):21-29.

66. Johnston MJW, Semple SC, Klimuk SK, Ansell S, Maurer N, Cullis PR. Characterization of the drug retention and pharmacokinetic properties of liposomal nanoparticles containing dihydrosphingomyelin. Biochim Biophys Acta. 2007;1768(5):1121-1127.
67. Fenske DB, MacLachlan I, Cullis PR. Long-circulating vectors for the systemic delivery of genes. Curr Opin Mol Ther. 2001;3(2):153-158.

68. Fenske DB, Cullis PR. Liposomal nanomedicines. Expert Opin Drug Deliv. 2008;5(1):25-44.

69. Semple SC, Leone R, Wang J, et al. Optimization and characterization of a sphingomyelin/cholesterol liposome formulation of vinorelbine with promising antitumor activity. J Pharm Sci. 2005;94(5):1024-1038.

70. Choudhuri T, Pal S, Das T, Sa G. Curcumin selectively induces apoptosis in deregulated cyclin D1-expressed cells at G2 phase of cell cycle in a p53-dependent manner. J Biol Chem. 2005;280(20):20059-20068.

71. Strijkers GJ, Kluza E, Van Tilborg GAF, et al. Paramagnetic and fluorescent liposomes for target-specific imaging and therapy of tumor angiogenesis. Angiogenesis. 2010;13(2):161-173.

72. Cheng AL, Hsu CH, Lin JK, et al. Phase I clinical trial of curcumin, a chemopreventive agent, in patients with high-risk or pre-malignant lesions. Anticancer Res. 2001;21(4B):2895-2900.

73. Thangapazham RL, Puri A, Tele S, Blumenthal R, Maheshwari RK. Evaluation of a nanotechnology-based carrier for delivery of curcumin in prostate cancer cells. Int J Oncol. 2008;32(5):1119-1123.

74. Fenske DB, Wong KF, Maurer E, et al. Ionophore-mediated uptake of ciprofloxacin and vincristine into large unilamellar vesicles exhibiting transmembrane ion gradients. Biochim Biophys Acta. 1998;1414(1-2):188-204

75. Johnston MJW, Semple SC, Klimuk SK, et al. Therapeutically optimized rates of drug release can be achieved by varying the drug-to-lipid ratio in liposomal vincristine formulations. Biochim Biophys Acta. 2006;1758(1):55-64.

76. Rodriguez MA, Dang NH, Fayad L, et al. Sphingosomal vincristine in $\mathrm{CHOP}$ is a promising new treatment for elderly, as well as poor prognosis patients with aggressive non-Hodgkin's lymphoma (NHL): follow-up results of a phase II study. J Clin Oncol. 2004;22(14S):8080.

77. Bhirde AA, Patel V, Gavard J, et al. Targeted killing of cancer cells in vivo and in vitro with EGF-directed carbon nanotube-based drug delivery. ACS Nano. 2009;3(2):307-316.

78. Liu Z, Chen K, Davis C, et al. Drug delivery with carbon nanotubes for in vivo cancer treatment. Cancer Res. 2008;68(16):6652-6660.

79. Chakravarty P, Marches R, Zimmerman NS, et al. Thermal ablation of tumor cells with antibody-functionalized single-walled carbon nanotubes. Proc Natl Acad Sci U S A. 2008;105(25):8697-8702.

80. Beg S, Rizwan M, Sheikh AM, Hasnain MS, Anwer K, Kohli K. Advancement in carbon nanotubes: basics, biomedical applications and toxicity. J Pharm Pharmacol. 2011;63(2):141-163.

81. Sobhani Z, Dinarvand R, Atyabi F, Ghahremani M, Adeli M. Increased paclitaxel cytotoxicity against cancer cell lines using a novel functionalized carbon nanotube. Int J Nanomedicine. 2011;6:705-719.

82. Khazaei A, Rad MNS, Borazjani MK. Organic functionalization of single-walled carbon nanotubes (SWCNTs) with some chemotherapeutic agents as a potential method for drug delivery. Int J Nanomedicine. 2010;5:639-645.

83. Krueger A. New carbon materials: biological applications of functionalized nanodiamond materials. Chemistry. 2008;14(5):1382-1390.

84. Kateb B, Chiu K, Black KL, et al. Nanoplatforms for constructing new approaches to cancer treatment, imaging, and drug delivery: what should be the policy? Neuroimage. 2011;54 Suppl 1:S106-S124.

85. Huang H, Pierstorff E, Osawa E, Ho D. Active nanodiamond hydrogels for chemotherapeutic delivery. Nano Lett. 2007;7(11):3305-3314.

86. Lam R, Chen M, Pierstorff E, Huang H, Osawa E, Ho D. Nanodiamondembedded microfilm devices for localized chemotherapeutic elution. ACS Nano. 2008;2(10):2095-2102.

87. Liu KK, Wang CC, Cheng CL, Chao JI. Endocytic carboxylated nanodiamond for the labeling and tracking of cell division and differentiation in cancer and stem cells. Biomaterials. 2009;30(26):4249-4259.

88. Sherman MB, Guenther RH, Tama F, et al. Removal of divalent cations induces structural transitions in red clover necrotic mosaic virus, revealing a potential mechanism for RNA release. JVirol. 2006;80(21):10395-10406.

89. Kwak M, Minten IJ, Anaya DM, et al. Virus-like particles templated by DNA micelles: a general method for loading virus nanocarriers. J Am Chem Soc. 2010;132(23):7834-7835. 
90. Dixit SK, Goicochea NL, Daniel MC, et al. Quantum dot encapsulation in viral capsids. Nano Lett. 2006;6(9):1993-1999.

91. Goicochea NL, De M, Rotello VM, Mukhopadhyay S, Dragnea B. Core-like particles of an enveloped animal virus can self-assemble efficiently on artificial templates. Nano Lett. 2007;7(8):2281-2290.

92. Klostergaard J, Seeney CE. Magnetic nanovectors for drug delivery. Maturitas. 2012.

93. Kale SN, Jadhav AD, Verma S, et al. Characterization of biocompatible $\mathrm{NiCo}_{2} \mathrm{O}_{4}$ nanoparticles for applications in hyperthermia and drug delivery. Nanomedicine. 2012;8(4):452-459.

94. Ahamed M, Akhtar MJ, Siddiqui MA, et al. Oxidative stress mediated apoptosis induced by nickel ferrite nanoparticles in cultured A549 cells. Toxicology. 2011;283(2-3):101-108.

95. Liu L, Zhang H, Meng X, Yin J, Li D, Liu C. Dinuclear metal(II) complexes of polybenzimidazole ligands as carriers for DNA delivery. Biomaterials. 2010;31(6):1380-1391.

96. Lai BB, Chen BA, Cheng J, et al. Daunorubicin-loaded magnetic nanoparticles of $\mathrm{Fe}_{3} \mathrm{O}_{4}$ greatly enhance the responses of multidrug-resistant K562 leukemic cells in a nude mouse xenograft model to chemotherapy. Zhongguo Shi Yan Xue Ye Xue Za Zh. 2009;17(2):345-351.

97. Andresen TL, Thompson DH, Kaasgaard T. Enzyme-triggered nanomedicine: drug release strategies in cancer therapy. Mol Membr Biol. 2010;27(7):353-363.

98. Gupta S, Andresen H, Ghadiali JE, Stevens MM. Kinase-actuated immunoaggregation of Peptide-conjugated gold nanoparticles. Small. 2010;6(14):1509-1513.

99. de la Rica R, Aili D, Stevens MM. Enzyme-responsive nanoparticles for drug release and diagnostics. Adv Drug Deliv Rev. Epub January 14, 2012.

100. Yang Y, Aw J, Chen K, et al. Enzyme-responsive multifunctional magnetic nanoparticles for tumor intracellular drug delivery and imaging. Chem Asian J. 2011;6(6):1381-1389.

101. Gupta S, Andresen H, Stevens MM. Single-step kinase inhibitor screening using a peptide-modified gold nanoparticle platform. Chem Commun (Camb). 2011;47(8):2249-2251.

102. Bharali DJ, Khalil M, Gurbuz M, Simone TM, Mousa SA. Nanoparticles and cancer therapy: a concise review with emphasis on dendrimers. Int J Nanomedicine. 2009;4:1-7.

103. Baker JR. Dendrimer-based nanoparticles for cancer therapy. Hematology Am Soc Hematol Educ Program. 2009;2009(1):708-719.

104. Svenson S, Tomalia DA. Dendrimers in biomedical applications reflections on the field. Adv Drug Deliv Rev. 2005;57(15):2106-2129.

105. Tekade RK, Kumar PV, Jain NK. Dendrimers in oncology: an expanding horizon. Chem Rev. 2009;109(1):49-87.

106. Menjoge AR, Kannan RM, Tomalia DA. Dendrimer-based drug and imaging conjugates: design considerations for nanomedical applications. Drug Discov Today. 2010;15(5-6):171-185.

107. Tomalia DA, Reyna LA, Svenson S. Dendrimers as multi-purpose nanodevices for oncology drug delivery and diagnostic imaging. Biochem Soc Trans. 2007;35(Pt 1):61-67.

108. Padilla De Jesús OL, Ihre HR, Gagne L, Fréchet JMJ, Szoka FC Jr. Polyester dendritic systems for drug delivery applications: in vitro and in vivo evaluation. Bioconjug Chem. 2002;13(3):453-461.

109. Lai PS, Lou PJ, Peng CL, et al. Doxorubicin delivery by polyamidoamine dendrimer conjugation and photochemical internalization for cancer therapy. J Control Release. 2007;122(1):39-46.

110. Kirkpatrick GJ, Plumb JA, Sutcliffe OB, Flint DJ, Wheate NJ. Evaluation of anionic half generation 3.5-6.5 poly(amidoamine) dendrimers as delivery vehicles for the active component of the anticancer drug cisplatin. J Inorg Biochem. 2011;105(9):1115-1122.

111. Gillies ER, Fréchet JMJ. Dendrimers and dendritic polymers in drug delivery. Drug Discov Today. 2005;10(1):35-43.

112. Malik N, Evagorou EG, Duncan R. Dendrimer-platinate: a novel approach to cancer chemotherapy. Anticancer Drugs. 1999;10(8):767-776.

113. Lee CC, Gillies ER, Fox ME, et al. A single dose of doxorubicinfunctionalized bow-tie dendrimer cures mice bearing C-26 colon carcinomas. Proc Natl Acad Sci U S A. 2006;103(45):16649-16654.
114. Maeda H, Wu J, Sawa T, Matsumura Y, Hori K. Tumor vascular permeability and the EPR effect in macromolecular therapeutics: a review. J Control Release. 2000;65(1-2):271-284.

115. Han G, Ghosh P, Rotello VM. Multi-functional gold nanoparticles for drug delivery. Adv Exp Med Biol. 2007;620:48-56.

116. Chen J, McLellan JM, Siekkinen A, Xiong Y, Li ZY, Xia Y. Facile synthesis of gold-silver nanocages with controllable pores on the surface. J Am Chem Soc. 2006;128(46):14776-14777.

117. Alkilany AM, Murphy CJ. Toxicity and cellular uptake of gold nanoparticles: what we have learned so far? J Nanopart Res. 2010;12(7):2313-2333.

118. Kim B, Han G, Toley BJ, Kim CK, Rotello VM, Forbes NS. Tuning payload delivery in tumour cylindroids using gold nanoparticles. Nat Nanotechnol. 2010;5(6):465-472.

119. Brown SD, Nativo P, Smith JA, et al. Gold nanoparticles for the improved anticancer drug delivery of the active component of oxaliplatin. J Am Chem Soc. 2010;132(13):4678-4684.

120. Khullar P, Singh V, Mahal A, et al. Bovine serum albumin bioconjugated gold nanoparticles: synthesis, hemolysis, and cytotoxicity toward cancer cell lines. J Phys Chem C. 2012;116(15):8834-8843.

121. Joshi P, Chakraborty S, Dey S, et al. Binding of chloroquineconjugated gold nanoparticles with bovine serum albumin. J Colloid Interface Sci. 2011;355(2):402-409.

122. Smith AM, Dave S, Nie S, True L, Gao X. Multicolor quantum dots for molecular diagnostics of cancer. Expert Rev Mol Diagn. 2006;6(2):231-244.

123. Gao X, Dave SR. Quantum dots for cancer molecular imaging. $A d v$ Exp Med Biol. 2007;620:57-73.

124. Yu Y, Xu L, Chen J, et al. Hydrothermal synthesis of GSH-TGA cocapped CdTe quantum dots and their application in labeling colorectal cancer cells. Colloids Surf B Biointerfaces. 2012;95:247-253.

125. Shen JM, Tang WJ, Zhang XL, Chen T, Zhang HX. A novel carboxymethyl chitosan-based folate $/ \mathrm{Fe}_{3} \mathrm{O}_{4} / \mathrm{CdTe}$ nanoparticle for targeted drug delivery and cell imaging. Carbohydr Polym. 2012;88(1): 239-249.

126. Li JM, Wang YY, Zhao MX, et al. Multifunctional QD-based co-delivery of siRNA and doxorubicin to HeLa cells for reversal of multidrug resistance and real-time tracking. Biomaterials. 2012;33(9):2780-2790.

127. Wang Y, Zhang Y, Du Z, Wu M, Zhang G. Detection of micrometastases in lung cancer with magnetic nanoparticles and quantum dots. Int J Nanomedicine. 2012;7:2315-2324.

128. Uner M, Yener G. Importance of solid lipid nanoparticles (SLN) in various administration routes and future perspectives. Int J Nanomedicine. 2007;2(3):289-300.

129. Wang S, Chen T, Chen R, Hu Y, Chen M, Wang Y. Emodin loaded solid lipid nanoparticles: preparation, characterization and antitumor activity studies. Int J Pharm. 2012;430(1-2):238-246.

130. Shi SJ, Zhong ZR, Liu J, Zhang ZR, Sun X, Gong T. Solid lipid nanoparticles loaded with anti-microRNA oligonucleotides (AMOs) for suppression of microRNA-21 functions in human lung cancer cells. Pharm Res. 2012;29(1):97-109.

131. Brewer E, Coleman J, Lowman A. Emerging technologies of polymeric nanoparticles in cancer drug delivery. J Nanomater. 2011;2011:1-10.

132. Rao JP, Geckeler KE. Polymer nanoparticles: preparation techniques and size-control parameters. Prog Polym Sci. 2011;36(7):887-913.

133. van Vlerken LE, Amiji MM. Multi-functional polymeric nanoparticles for tumour-targeted drug delivery. Expert Opin Drug Deliv. 2006;3(2):205-216.

134. Owens DE 3rd, Peppas NA. Opsonization, biodistribution, and pharmacokinetics of polymeric nanoparticles. Int J Pharm. 2006;307(1):93-102.

135. Hu S, Zhang Y. Endostar-loaded PEG-PLGA nanoparticles: in vitro and in vivo evaluation. Int J Nanomedicine. 2010;5:1039-1048.

136. Woo HN, Chung HK, Ju EJ, et al. Preclinical evaluation of injectable sirolimus formulated with polymeric nanoparticle for cancer therapy. Int J Nanomedicine. 2012;7:2197-2208. 
137. Aravind A, Jeyamohan P, Nair R, et al. AS1411 aptamer tagged PLGAlecithin-PEG nanoparticles for tumor cell targeting and drug delivery. Biotechnol Bioeng. Epub May 21, 2012.

138. Guo J, Gao X, Su L, et al. Aptamer-functionalized PEG-PLGA nanoparticles for enhanced anti-glioma drug delivery. Biomaterials. 2011;32(31):8010-8020.

139. Dhar S, Gu FX, Langer R, Farokhzad OC, Lippard SJ. Targeted delivery of cisplatin to prostate cancer cells by aptamer functionalized Pt(IV) prodrug-PLGA-PEG nanoparticles. Proc Natl Acad Sci U SA. 2008;105(45):17356-17361.

140. Chen J, Li S, Shen Q, He H, Zhang Y. Enhanced cellular uptake of folic acid-conjugated PLGA-PEG nanoparticles loaded with vincristine sulfate in human breast cancer. Drug Dev Ind Pharm. 2011;37(11):1339-1346.

141. Cho H, Bae J, Garripelli VK, Anderson JM, Jun HW, Jo S. Redoxsensitive polymeric nanoparticles for drug delivery. Chem Commun (Camb). 2012.

142. Prajapati BG. Nanoparticles as platforms for targeted drug delivery system in cancer therapy. Internet J Nanotechnol. 2009;3(1):1-8.

143. Stern JM, Cadeddu JA. Emerging use of nanoparticles for the therapeutic ablation of urologic malignancies. Urol Oncol. 2008;26(1):93-96.

144. Milleron RS, Bratton SB. 'Heated' debates in apoptosis. Cell Mol Life Sci. 2007;64(18):2329-2333.

145. Cherukuri P, Glazer ES, Curley SA. Targeted hyperthermia using metal nanoparticles. Adv Drug Deliv Rev. 2010;62(3):339-345.

146. Ellis LM, Curley SA, Tanabe KK. Radiofrequency Ablation for Cancer: Current Indications, Techniques, and Outcomes. New York: SpringerVerlag; 2004.

147. Mody VV, Siwale R, Singh A, Mody HR. Introduction to metallic nanoparticles. J Pharm Bioallied Sci. 2010;2(4):282-289.

148. Samanta B, Yan H, Fischer NO, Shi J, Jerry DJ, Rotello VM. Proteinpassivated $\mathrm{Fe}_{3} \mathrm{O}_{4}$ nanoparticles: low toxicity and rapid heating for thermal therapy. J Mater Chem. 2008;18(11):1204-1208.

149. Kam NWS, Liu Z, Dai H. Functionalization of carbon nanotubes via cleavable disulfide bonds for efficient intracellular delivery of siRNA and potent gene silencing. J Am Chem Soc. 2005;127(36):12492-12493.

150. Gannon CJ, Cherukuri P, Yakobson BI, et al. Carbon nanotubeenhanced thermal destruction of cancer cells in a noninvasive radiofrequency field. Cancer. 2007;110(12):2654-2665.

151. Samia ACS, Chen X, Burda C. Semiconductor quantum dots for photodynamic therapy. J Am Chem Soc. 2003;125(51):15736-15737.

152. Bakalova R, Ohba H, Zhelev Z, Ishikawa M, Baba Y. Quantum dots as photosensitizers? Nat Biotechnol. 2004;22(11):1360-1361.

153. Letfullin RR, Iversen CB, George TF. Modeling nanophotothermal therapy: kinetics of thermal ablation of healthy and cancerous cell organelles and gold nanoparticles. Nanomedicine. 2011;7(2):137-145.

154. Fillat C, Jose A, Bofill-DeRos X, Mato-Berciano A, Maliandi MV, Sobrevals L. Pancreatic cancer gene therapy: from molecular targets to delivery systems. Cancers. 2011;3(1):368-395.

155. Song WJ, Du JZ, Sun TM, Zhang PZ, Wang J. Gold nanoparticles capped with polyethyleneimine for enhanced siRNA delivery. Small. 2010;6(2):239-246

156. Liu J, Sonshine DA, Shervani S, Hurt RH. Controlled release of biologically active silver from nanosilver surfaces. ACS Nano. 2010;4(11):6903-6913.

157. Nunes A, Amsharov N, Guo C, et al. Hybrid polymer-grafted multiwalled carbon nanotubes for in vitro gene delivery. Small. 2010;6(20):2281-2291.

158. Ewert KK, Zidovska A, Ahmad A, et al. Cationic liposome-nucleic acid complexes for gene delivery and silencing: pathways and mechanisms for plasmid DNA and siRNA. Top Curr Chem. 2010;296:191-226.

159. Tanner P, Baumann P, Enea R, Onaca O, Palivan C, Meier W. Polymeric vesicles: from drug carriers to nanoreactors and artificial organelles. Acc Chem Res. 2011;44(10):1039-1049.

160. Kim TH, Jin H, Kim HW, Cho MH, Cho CS. Mannosylated chitosan nanoparticle-based cytokine gene therapy suppressed cancer growth in BALB/c mice bearing CT-26 carcinoma cells. Mol Cancer Ther. 2006;5(7):1723-1732.
161. Talaei F, Azizi E, Dinarvand R, Atyabi F. Thiolated chitosan nanoparticles as a delivery system for antisense therapy: evaluation against EGFR in T47D breast cancer cells. Int J Nanomedicine. 2011;6:1963-1975.

162. Pirollo KF, Rait A, Zhou Q, et al. Materializing the potential of small interfering RNA via a tumor-targeting nanodelivery system. Cancer Res. 2007;67(7):2938-2943.

163. Gopalan B, Ito I, Branch CD, Stephens C, Roth JA, Ramesh R. Nanoparticle based systemic gene therapy for lung cancer: molecular mechanisms and strategies to suppress nanoparticle-mediated inflammatory response. Technol Cancer Res Treat. 2004;3(6):647-657.

164. Zhang L, Gao X, Men K, et al. Gene therapy for C-26 colon cancer using heparin-polyethyleneimine nanoparticle-mediated survivin T34A. Int J Nanomedicine. 2011;6:2419-2427.

165. Xu Z, Shen G, Xia X, et al. Comparisons of three polyethyleneiminederived nanoparticles as a gene therapy delivery system for renal cell carcinoma. J Transl Med. 2011;9(1):46-46.

166. Chen AA, Derfus AM, Khetani SR, Bhatia SN. Quantum dots to monitor RNAi delivery and improve gene silencing. Nucleic Acids Res. 2005;33(22):e190.

167. Xie J, Lee S, Chen X. Nanoparticle-based theranostic agents. Adv Drug Deliv Rev. 2010;62(11):1064-1079.

168. Cai D, Mataraza JM, Qin ZH, et al. Highly efficient molecular delivery into mammalian cells using carbon nanotube spearing. Nat Methods. 2005;2(6):449-454.

169. Elhissi AMA, Ahmed W, Hassan IU, Dhanak VR, D'Emanuele A. Carbon nanotubes in cancer therapy and drug delivery. J Drug Deliv. 2012;2012:Article ID 837327.

170. Podesta JE, Al-Jamal KT, Herrero MA, et al. Antitumor activity and prolonged survival by carbon-nanotube-mediated therapeutic siRNA silencing in a human lung xenograft model. Small. 2009;5(10):1176-1185.

171. Barker SL, Shortreed MR, Kopelman R. Utilization of lipophilic ionic additives in liquid polymer film optodes for selective anion activity measurements. Anal Chem. 1997;69(6):990-995.

172. Choi Y, Thomas T, Kotlyar A, Islam MT, Baker JR Jr. Synthesis and functional evaluation of DNA-assembled polyamidoamine dendrimer clusters for cancer cell-specific targeting. Chem Biol. 2005;12(1): 35-43.

173. Duncan R MN. Dendrimers: biocompatibility and potential for delivery of anticancer agents. Proc Int Symp Control Release Bioact Mater. 1996;23:105-106.

174. Varkouhi AK, Foillard S, Lammers T, et al. SiRNA delivery with functionalized carbon nanotubes. Int J Pharm. 2011;416(2):419-425.

175. Yao H, Ng SS, Huo LF, et al. Effective melanoma immunotherapy with interleukin-2 delivered by a novel polymeric nanoparticle. Mol Cancer Ther. 2011;10(6):1082-1092.

176. Prakash S, Wei Shao M, Paul A, et al. A novel polyethyleneiminecoated adeno-associated virus-like particle formulation for efficient siRNA delivery in breast cancer therapy: preparation and in vitro analysis. Int J Nanomedicine. 2012:1575-1586.

177. Fortina P, Kricka LJ. Nanotechnology: improving clinical testing? Clin Chem. 2010;56(9):1384-1389.

178. Chi X, Huang D, Zhao Z, Zhou Z, Yin Z, Gao J. Nanoprobes for in vitro diagnostics of cancer and infectious diseases. Biomaterials. 2012;33(1):189-206.

179. Sullivan DC, Ferrari M. Nanotechnology and tumor imaging: seizing an opportunity. Mol Imaging. 2004;3(4):364-369.

180. Medintz IL, Uyeda HT, Goldman ER, Mattoussi H. Quantum dot bioconjugates for imaging, labelling and sensing. Nat Mater. 2005;4(6): 435-446.

181. Pericleous P, Gazouli M, Lyberopoulou A, Rizos S, Nikiteas N, Efstathopoulos EP. Quantum dots hold promise for early cancer imaging and detection. Int J Cancer. 2012;131(3):519-528.

182. Smith AM, Duan H, Mohs AM, Nie S. Bioconjugated quantum dots for in vivo molecular and cellular imaging. Adv Drug Deliv Rev. 2008;60(11):1226-1240.

183. Gao J, Chen X, Cheng Z. Near-infrared quantum dots as optical probes for tumor imaging. Curr Top Med Chem. 2010;10(12):1147-1157. 
184. Frasco MF, Chaniotakis N. Semiconductor quantum dots in chemical sensors and biosensors. Sensors (Basel). 2009;9(9):7266-7286.

185. Hu M, Yan J, He Y, et al. Ultrasensitive, multiplexed detection of cancer biomarkers directly in serum by using a quantum dot-based microfluidic protein chip. ACS Nano. 2010;4(1):488-494.

186. Bailey VJ, Easwaran H, Zhang Y, et al. MS-qFRET: a quantum dot-based method for analysis of DNA methylation. Genome Res. 2009;19(8):1455-1461.

187. So MK, Xu C, Loening AM, Gambhir SS, Rao J. Self-illuminating quantum dot conjugates for in vivo imaging. Nat Biotechnol. 2006;24(3):339-343.

188. Xia Z, Xing Y, So MK, Koh AL, Sinclair R, Rao J. Multiplex detection of protease activity with quantum dot nanosensors prepared by intein-mediated specific bioconjugation. Anal Chem. 2008;80(22):8649-8655.

189. Jun YW, Sheikholeslami S, Hostetter DR, Tajon C, Craik CS, Alivisatos AP. Continuous imaging of plasmon rulers in live cells reveals earlystage caspase-3 activation at the single-molecule level. Proc Natl Acad Sci USA. 2009;106(42):17735-17740.

190. Lee SE, Lee LP. Biomolecular plasmonics for quantitative biology and nanomedicine. Curr Opin Biotechnol. 2010;21(4):489-497.

191. Osterfeld SJ, Yu H, Gaster RS, et al. Multiplex protein assays based on real-time magnetic nanotag sensing. Proc Natl Acad Sci U S A. 2008;105(52):20637-20640.

192. Hirsch LR, Jackson JB, Lee A, Halas NJ, West JL. A whole blood immunoassay using gold nanoshells. Anal Chem. 2003;75(10): 2377-2381.

193. Zhao X, Tapec-Dytioco R, Tan W. Ultrasensitive DNA detection Soc. 2003;125(38):11474-11475.

194. Wu X, Liu H, Liu J, et al. Immunofluorescent labeling of cancer marker Her2 and other cellular targets with semiconductor quantum dots. Nat Biotechnol. 2003;21(1):41-46.

195. Santra S, Zhang P, Wang K, Tapec R, Tan W. Conjugation of biomolecules with luminophore-doped silica nanoparticles for photostable biomarkers. Anal Chem. 2001;73(20):4988-4993.

196. Riehemann K, Schneider SW, Luger TA, Godin B, Ferrari M, Fuchs H. Nanomedicine - challenge and perspectives. Angew Chem Int Ed Engl. 2009;48(5):872-897.

197. Yue M, Lin H, Dedrick DE, et al. A 2-D microcantilever array for multiplexed biomolecular analysis. J Microelectromech Syst. 2004;13(2):290-299.

198. Majumdar A. Bioassays based on molecular nanomechanics. Dis Markers. 2002;18(4):167-174.

199. Zheng G, Patolsky F, Cui Y, Wang WU, Lieber CM. Multiplexed electrical detection of cancer markers with nanowire sensor arrays. Nat Biotechnol. 2005;23(10):1294-1301.

200. Stern E, Vacic A, Rajan NK, et al. Label-free biomarker detection from whole blood. Nat Nanotechnol. 2010;5(2):138-142.

201. Sun YP, Fu K, Lin Y, Huang W. Functionalized carbon nanotubes: properties and applications. Acc Chem Res. 2002;35(12):1096-1104.

202. Liu Z, Tabakman S, Welsher K, Dai H. Carbon nanotubes in biology and medicine: in vitro and in vivo detection, imaging and drug delivery. Nano Res. 2009;2(2):85-120.

203. Park JH, von Maltzahn G, Ruoslahti E, Bhatia SN, Sailor MJ. Micellar hybrid nanoparticles for simultaneous magnetofluorescent imaging and drug delivery. Angew Chem Int Ed Engl. 2008;47(38):7284-7288. using highly fluorescent bioconjugated nanoparticles. J Am Chem

204. Mistlberger G, Koren K, Scheucher E, et al. Multifunctional magnetic optical sensor particles with tunable sizes for monitoring metabolic parameters and as a basis for nanotherapeutics. Adv Funct Mater. 2010;20(11):1842-1851.

205. Yong KT. Biophotonics and biotechnology in pancreatic cancer: cyclic RGD-peptide-conjugated type II quantum dots for in vivo imaging. Pancreatology. 2010;10(5):553-564.

206. Bünzli JC. Lanthanide luminescence for biomedical analyses and imaging. Chem Rev. 2010;110(5):2729-2755.

207. Sitharaman B, Avti. Luminescent single-walled carbon nanotube-sensitized europium nanoprobes for cellular imaging. Int $J$ Nanomedicine. 2012:1953-1953.

208. Lewis DJ, Bruce C, Bohic S, et al. Intracellular synchrotron nanoimaging and DNA damage/genotoxicity screening of novel lanthanide-coated nanovectors. Nanomedicine (Lond). 2010;5(10): 1547-1557.

209. Liu Y, Zhang N. Gadolinium loaded nanoparticles in theranostic magnetic resonance imaging. Biomaterials. 2012;33(21):5363-5375.

210. Wang X, Wang C, Cheng L, Lee ST, Liu Z. Noble metal coated single-walled carbon nanotubes for applications in surface enhanced Raman scattering imaging and photothermal therapy. JAm Chem Soc. 2012;134(17):7414-7422.

211. Cordovilla C, Swager TM. Strain release in organic photonic nanoparticles for protease sensing. J Am Chem Soc. 2012;134(16): 6932-6935.

212. Ling Y, Wei K, Zou F, Zhong S. Temozolomide loaded PLGAbased superparamagnetic nanoparticles for magnetic resonance imaging and treatment of malignant glioma. Int J Pharm. 2012;430(1-2):266-275.

213. Dong H, Lei J, Ju H, et al. Target-cell-specific delivery, imaging, and detection of intracellular MicroRNA with a multifunctional $\mathrm{SnO}_{2}$ nanoprobe. Angew Chem Int Ed Engl. 2012;51(19):4607-4612.

214. Tao L, Zhang K, Sun Y, Jin B, Zhang Z, Yang K. Anti-epithelial cell adhesion molecule monoclonal antibody conjugated fluorescent nanoparticle biosensor for sensitive detection of colon cancer cells. Biosens Bioelectron. 2012;35(1):186-192.

215. Liu K, Liu X, Zeng Q, et al. Covalently assembled NIR Nanoplatform for simultaneous fluorescence imaging and photodynamic therapy of cancer cells. ACS Nano. 2012;6(5):4054-4062.

216. Ferguson RM, Khandhar AP, Krishnan KM. Tracer design for magnetic particle imaging (invited). J Appl Phys. 2012;111(7): 7B318-317B3185.

217. Puvanakrishnan P, Diagaradjane P, Kazmi SMS, Dunn AK, Krishnan S, Tunnell JW. Narrow band imaging of squamous cell carcinoma tumors using topically delivered anti-EGFR antibody conjugated gold nanorods. Lasers Surg Med. 2012;44(4):310-317.

218. El-Dakdouki MH, Zhu DC, El-Boubbou K, et al. Development of multifunctional hyaluronan-coated nanoparticles for imaging and drug delivery to cancer cells. Biomacromolecules. 2012;13(4): 1144-1151.

219. Cho K, Wang X, Nie S, Chen Z and Shin DM. Therapeutic Nanoparticles for Drug Delivery in Cancer. Clin Cancer Res. 2008;14:1310-1316.

220. McBain SC, Yiu HHP, Dobson J. Magnetic nanoparticles for gene and drug delivery. Int J Nanomedicine. 2008;3(2):169-180.

\section{Dovepress}

\section{Publish your work in this journal}

The International Journal of Nanomedicine is an international, peerreviewed journal focusing on the application of nanotechnology in diagnostics, therapeutics, and drug delivery systems throughout the biomedical field. This journal is indexed on PubMed Central, MedLine, CAS, SciSearch $\AA$, Current Contents ${ }^{\circledR} /$ Clinical Medicine,

Journal Citation Reports/Science Edition, EMBase, Scopus and the Elsevier Bibliographic databases. The manuscript management system is completely online and includes a very quick and fair peer-review system, which is all easy to use. Visit http://www.dovepress.com/ testimonials.php to read real quotes from published authors. 